
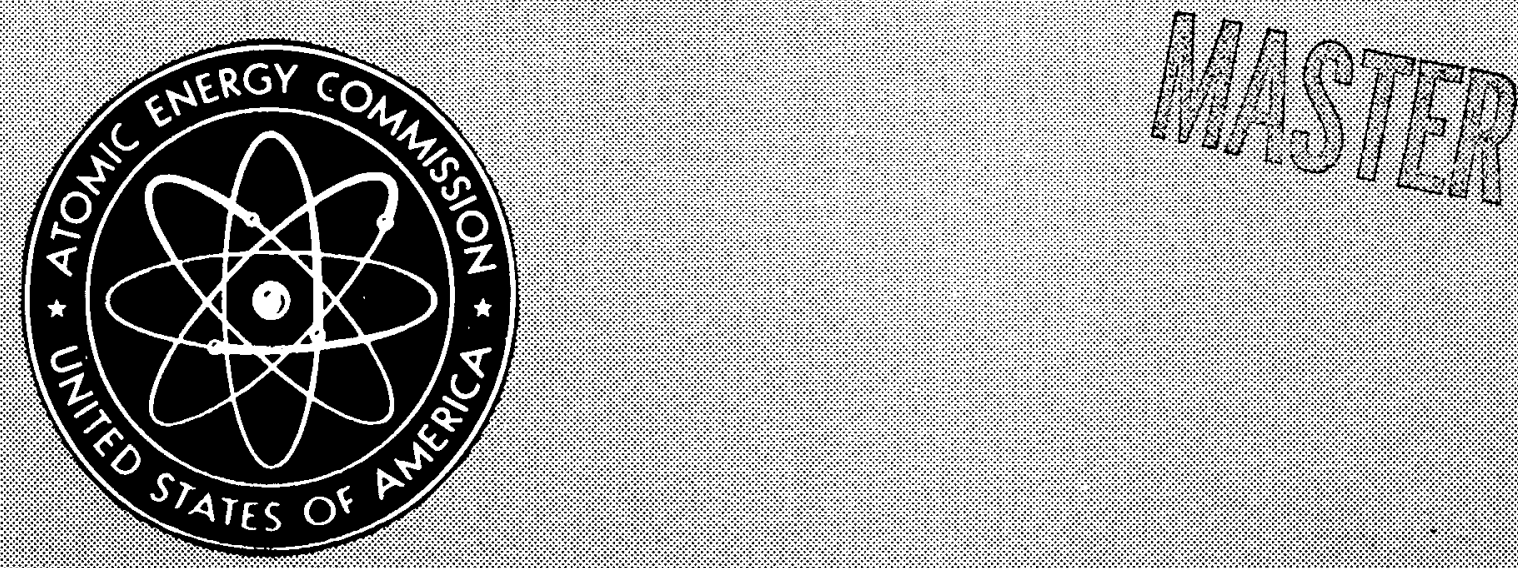

HASL - 150

\title{
SPECTROMETRIC TECHNIQUES FOR MEASURING ENVIRONMENTAL GAMMA RADIATION
}

By

Harold L. Beck

William J. Condon

Wayne M. Lowder

October 1964

Health and Safety Laboratory

New York Operations Office, AEC

New York, New York 


\section{DISCLAIMER}

This report was prepared as an account of work sponsored by an agency of the United States Government. Neither the United States Government nor any agency Thereof, nor any of their employees, makes any warranty, express or implied, or assumes any legal liability or responsibility for the accuracy, completeness, or usefulness of any information, apparatus, product, or process disclosed, or represents that its use would not infringe privately owned rights. Reference herein to any specific commercial product, process, or service by trade name, trademark, manufacturer, or otherwise does not necessarily constitute or imply its endorsement, recommendation, or favoring by the United States Government or any agency thereof. The views and opinions of authors expressed herein do not necessarily state or reflect those of the United States Government or any agency thereof. 


\section{DISCLAIMER}

Portions of this document may be illegible in electronic image products. Images are produced from the best available original document. 


\section{LEGAL NOTICE}

This report was prepared as an account of Government sponsored work. Neither the United States, nor the Commission, nor any person acting on behalf of the Commission:

A. Makes any warranty or representation, expressed or implied, with respect to the accuracy, completeness, or usefulness of the information contained in this report, or that the use of any information, apparatus, method, or process disclosed in this report may not infringe privately owned rights; or

B. Assumes any liabilities with respect to the use of, or for damages resulting from the use of any information, apparatus, method, or process disclosed in this report.

As used in the above, "person acting on behalf of the Commission" inciudes any employee or contractor of the Commission, or employee of such contractor, to the extent that such employee or contractor of the Commission, or employee of such contractor prepares, disseminates, or provides access to, any information pursuant to his employment or contract with the Commission, or his employment with such contractor.

This report has been reproduced directly from the best available copy.

Printed in USA. Price $\$ 3.00$. Available from the Clearinghouse for Federal Scientific and Technical Information, National Bureau of Standards, U. S. Department of Commerce, Springfield, Va. 
HASL - 150

HEALTH AND SAFETY

(TID -4500 , 37th. Ed.)

\title{
SPECTROMETRIC TECHNIQUES FOR MEASURING ENVIRONMENTAL GAMMA RADIATION
}

\author{
Harold I. Beck \\ William J. Condon \\ Wayne M. Lowder
}

October 1964

\section{HEALTH AND SAFETY LABORATORY \\ U. S. ATOMIC ENERGY COMMISSION NEW YORK, NEW YORK}

This document is

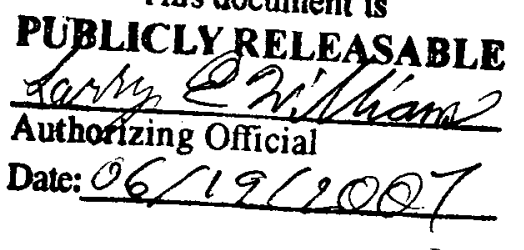




\section{ABSTRACT}

Pulse height spectra obtained in the field using a large NaI(TI) crystal can be analyzed by relatively unsophisticated methods to determine accurately total environmental $\gamma$-ray dose rates, as well as the individual dose rate contributions from $\mathrm{K}^{40}$, the $\mathrm{U}^{238}$ series, the Th232 series, and the principal $\gamma$-ray emitting fission products. The calibration of a 5-in. by 3-in. detector is described in detail, and the applicability and limitations of the spectral analysis methods are examined.

Several problems associated with field measurements are discussed, in particular the effects of radon migration from the soil, soil moisture, and natural fallout. Evidence is presented to demonstrate the validity and utility of dosimetric and related information obtained from field spectra analyzed by these methods. 
TABLE OF CONTENTS

TEXT

$\underline{\text { Page }}$

I. INTRODUCTION. ...................... I

II. INSTRUMENTATION. ..................... 2

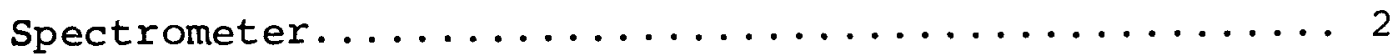

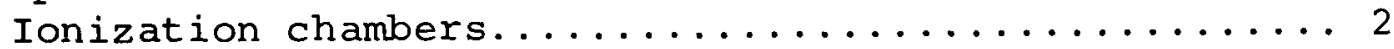

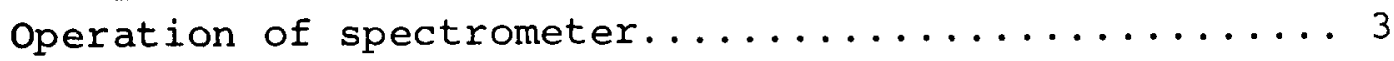

III. SPECTROMETRIC DETERMINATION OF TOTAL TERRESTRIAL

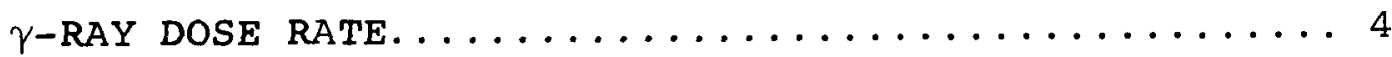

Field calibration of spectrum "energy"........... 4

Laboratory calibration of spectrum "energy". . . . . . . . 4 4

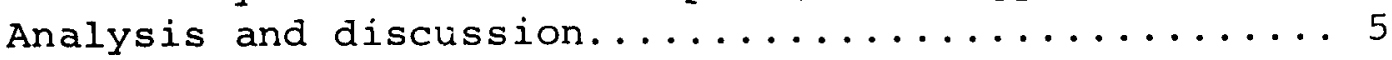

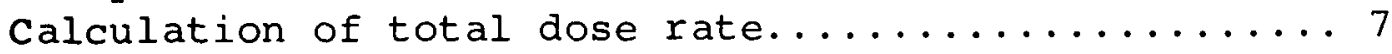

IV. SPECTROMETRIC DETERMINATION OF COMPONENT DOSE RATE

CONTRIBUTIONS - PEAK METHOD............... 9

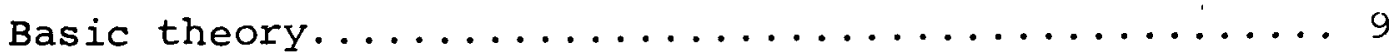

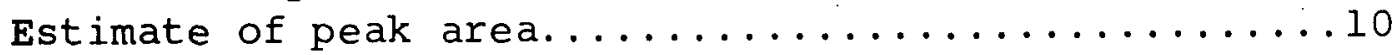

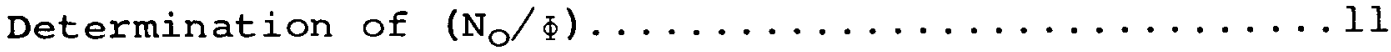

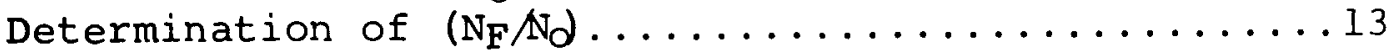

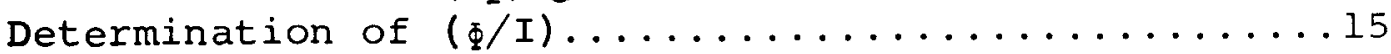

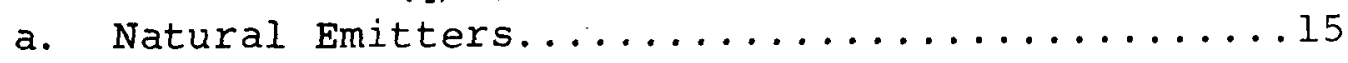

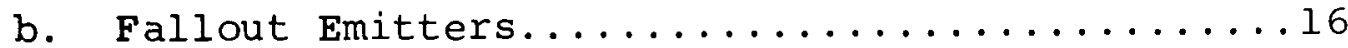

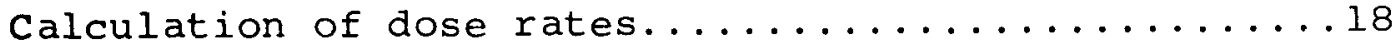

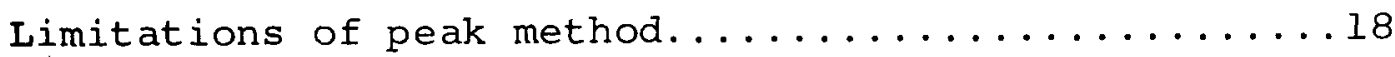

V. SPECTROMETRIC DETERMINATION OF COMPONENT DOSE RATE CONTRIBUTIONS - "ENERGY BAND" METHOD............ 20

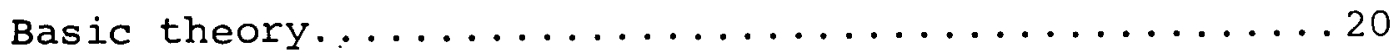

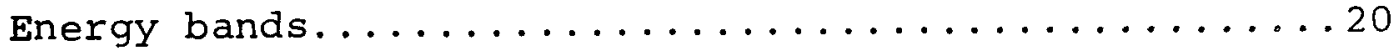

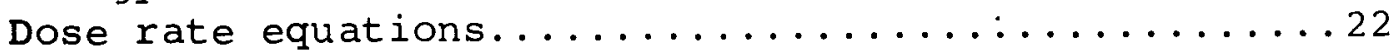

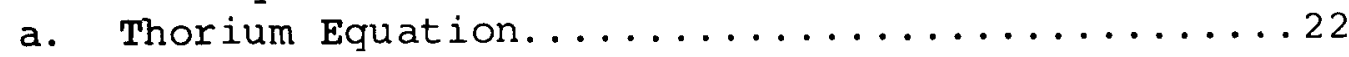

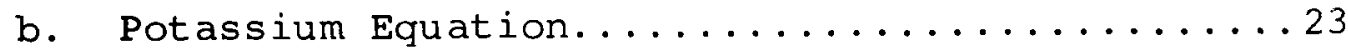

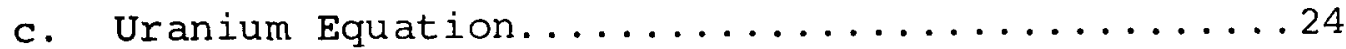

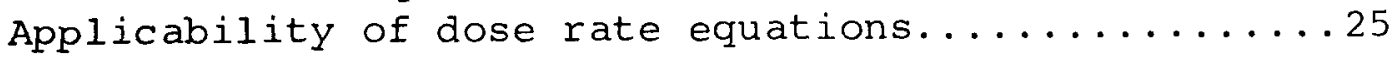




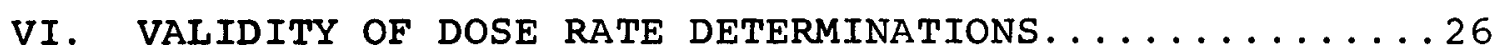

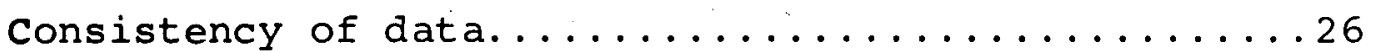

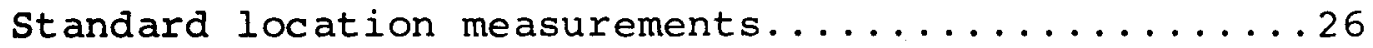

Intercomparison with field measurements by others...27

Intercomparison with laboratory soil sample

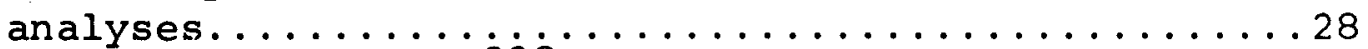

Discussion of the $\mathrm{U}^{238}$ series intercomparison.....28

Total terrestrial $\gamma$ and cosmic ray dose rates.......31

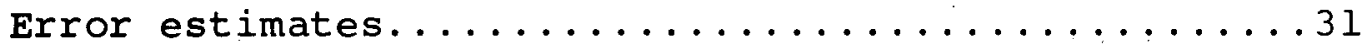

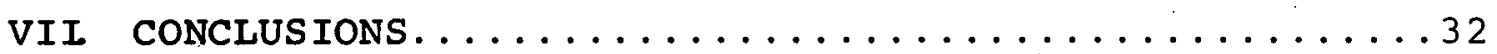

\section{APPENDICES}

Appendix I. Dose rate from an exponentially distributed

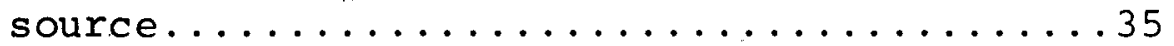

Appendix II Fallout age determination...............

\section{TABLES}

Table I. Important fallout $\gamma$ emitters.............40

Table II. Calibration sources....................

Table III. Calibration of NaI(TI) detector.........42

Table IV. Dose rate calibration of detector natural emitters...................43

Table V. Dose rate calibration of detector -

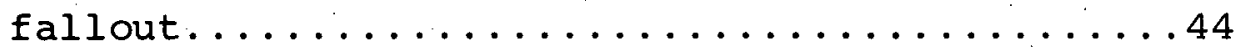

Table VI. Representative survey results............45 
TABLE OF CONTENTS (Cont'd)

Page

ILLUSTRATIONS

Figure 1. Detector assembly................46

Figure 2. Equipment set up for typical measurement....47

Figure 3. Two typical field spectra............48

Figure 4. Spectrum "energy" vs. terrestrial dose rate

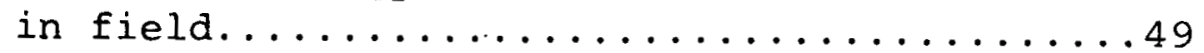

Figure 5. Spectrum "energy" vs. dose rate produced by $\mathrm{Ra}^{2} 26$ source..........................

Figure 6. Angular response of detector............51

Figure 7. Angular primary flux distribution at 1 meter

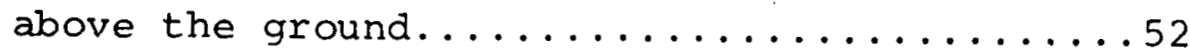

Figure 8. NaI-air relative response curve.........53

Figure 9. Integral $\gamma-r a y$ dose rate distributions from ground half space and from $\mathrm{Ra}^{226}$ source.....54

Figure 10. Experimental integral distributions of spectrum "energy" for various fallout levels.......55

Figure 11. Field spectrum obtained near copperopolis,

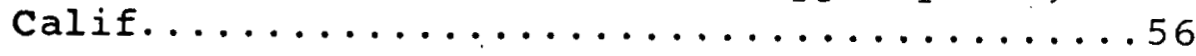

Figure 12. Absorption peak area estimates..........57

Figure 13. $k^{42}$ peak counts vs. incident primary flux...58

Figure 14. $\quad \mathrm{Tl}^{208}$ peak counts vs. incident primary flux............................ 59 
TABLE OF CONTENTS (Cont'd)

$\underline{\text { Page }}$

Figure 15. Intrinsic peak efficiency of crystal......60

Figure 16. Fallout dose rates in Westchester Ca, N.Y...61

Figure 17. $2.62 \mathrm{MeV}$ peak counts vs. in situ soil content determinations...............62

Figure 18. In situ $T_{2} 232$ soil content vs. HASL $T^{232}$ series dose rate estimates............663

Figure 19. Th232 soil content determined by soil sample analysis vs. HASL $\mathrm{Th} 232$ series dose rate....64 64

Figure 20. Potassium soil content determined by soil sample analysis vs. HASL $\mathrm{K} 40$ dose rate.....65

Figure 21. $\mathrm{U}^{238}$ soil content determined by soil sample analysis vs. HASL U238 series dose rate....66

Figure 22. Peak area ratios vs. fallout age........67

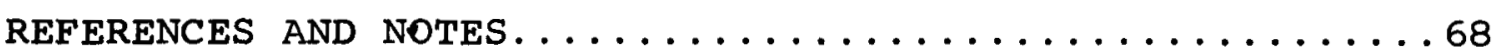




\section{INTRODUCTION}

Estimates of long-term exposure to environmental radiation require detailed information on the properties of the environmental radiation field in areas of human habitation and activity. In the past, the Health and safety Laboratory (HASL) has relied on sensitive ionization chamber measurements for determining total dose rates from the more penetrating components, primarily $\gamma$-rays from terrestrial sources and the high energy secondaries produced in the atmosphere by cosmic radiation ${ }^{1 / 2}$. The significant contribution in recent years from $\gamma$-ray emitting fallout to this total dose rate has necessitated the development of techniques for determining the individual dose rate contributions of the various important natural and fallout $\gamma$ emitters. Pulse height spectra obtained by us at over 200 different locations in the United States, supplemented by precise measurements of total terrestrial $\gamma$-ray and cosmic ray dose rates with high pressure ionization chambers, have allowed important conclusions on the structure of environmental radiation fields and the influence of fallout to be made ${ }^{3-7}$. In this report we describe the technigues developed to allow reasonably precise and accurate estimates of the dose rate contributions from the $\gamma$-rays of $\mathrm{K}^{40}$ and the daughters of $\mathrm{U}^{238}$ and $\mathrm{Th}^{232}$ as well as from the $\gamma$-rays of $\mathrm{Zr}^{95}$, Nb95, $\mathrm{Cs}^{137}$, and $\mathrm{Rh}^{106}$ to be obtained from such field spectra. We discuss in detail the equipment, calibration procedures, and technigues used to analyze the spectra, present evidence to substantiate the validity of the dose rate estimates, and examine several problems associated with field measurements, in particular the effects of radon migration from the soil, soil moisture, and natural fallout. 


\section{INSTRUMENTATION}

\section{Spectrometer}

The detector we use is a 3" high by 5" diameter NaI(T1) crystal shielded only by a thin aluminum container. A crystal this large is necessary to provide prominent total absorption peaks. The crystal is coupled to a 5 " photomultiplier tube: The photomultiplier high voltage is supplied by a 1100 volt Nuclear Data battery pack. The detector assembly is shown in Figure 1 .

The crystal assembly is mounted on a small wooden tripod 1 meter above the ground in the center of the area to be surveyed (usually a large, flat, grassy area at least 30 feet in diameter) with the plane surface facing downward through a hole in the platform of the tripod. The photomultiplier tube is connected to a multi-channel pulse height analyzer by a 50 foot coaxial cable. The read-out system consists of both an IBM typewriter and a Tally paper tape punch. The entire system is mounted in the HASL Corvan vehicle, and power to operate the electronic equipment is supplied by the car battery through a 12 volt DC to 115 volt AC converter. The converter is a carter 300 watt rotary inverter and is sufficient to power both the analyzer and typewriter. The spectrometer and a high pressure ionization chamber are shown set up at a typical location in Figure 2.

\section{Ionization chambers}

Our standard instruments for measuring total dose rates from penetrating radiations are two 8-liter ionization chambers filled to 625 psi with pure argon gas. Compared with previously-utilized unpressurized 20-liter air chambers ${ }^{2}$, these chambers provide much larger ionization currents per unit dose rate and greater reliability under the stress of field surveys, at the sacrifice of easy interpretability of measurements in terms of air dose rates. These 1/8-inch steel-walled pressurized chambers are completely portable, with battery-operated electrometers mounted directly above the chambers themselves. Careful calibrations of these chambers have been carried out for cosmic rays ${ }^{8}$ and for $\gamma$-rays of various energies ${ }^{2}$. 


\section{Operation of spectrometer}

The gain of the pulse height analyzer is adjusted to provide a spectrum ranging from 0 to about $3.5 \mathrm{MeV}$. Data is then accumulated for twenty minutes live time. This length of time has been found to provide sufficiently detailed spectra for our purposes. Two typical spectra are shown in Figure 3. The data can be read out on punched tape as well as by typewriter and this tape is read directly into an IBM 1620 computer for part of the analysis.

Two of our spectral analysis methods require a determination of the mean energy corresponding to each analyzer channel. Pulse height analyzer systems are of course fairly sensitive to environmental conditions which frequently will cause gain and zero variations. These conditions can be carefully controlled in the laboratory, but in the field gradual changes in the gain and zero of the analyzer system are unavoidable. However, such changes have not been severe over the course of any particular twenty minute data accumulation period, and thus the zero and energy calibration for each spectrum could usually be obtained from the spectrum itself. The prominent $0.75 \mathrm{MeV}\left(\mathrm{Zr}^{95}-\mathrm{Nb} 95\right)$ and $1.46 \mathrm{MeV}$ $\left(\mathrm{K}^{40}\right)$ peaks present in nearly all the spectra allowed fairly precise determinations of these parameters. When considered necessary, a weak $\mathrm{Na}^{22}$ source $(0.51 \mathrm{MeV}, 1.28 \mathrm{MeV})$ was analyzed both before and after the actual data run as a further check on the gain and zero of the system. 


\section{SPECTROMETRIC DETERMINATION OF TOTAL TERRESTRIAL $\gamma$-RAY DOSE RATE}

\section{Field calibration of spectrum "energy"}

We have found that the total "energy" (the sum over the corresponding channel range of the counts per channel multiplied by the mean $\gamma$-ray energy corresponding to that channel) in the spectrum from $0.15 \mathrm{MeV}$ to $3.4 \mathrm{MeV}$ is a quantity closely proportional to the total $\gamma$-ray dose rate from terrestrial sources, as determined from the ionization chamber terrestrial dose rates for a number of locations surveyed in April, 1963 (Figure 4). Although these locations were at roughly the same altitude, the ratio of the fallout dose rate to the total dose rate varied considerably. from location to location with no apparent effect. The slope of the line indicates a conversion factor of $44.2 \mathrm{BeV} / \mu \mathrm{r} / \mathrm{hr}$.

In addition to the April, 1963, survey data (Figure 4), plots of spectrum "energy" versus ion chamber terrestrial dose rate for over 100 other measurements in the western, central, and northeastern U. S. exhibited linear correlations quite as good as that of Figure 4, and with the same slope $(+5 \%)$. Since these measurements encompassed a wide range of altitudes (i.e., cosmic ray levels), fallout levels, and natural $\gamma$-ray levels, it is evident that the spectrometer can be used to obtain precise values for total terrestrial $\gamma$-ray dose rates in most situations likely to be encountered in the field.

\section{Laboratory calibration of spectrum "energy"}

An attempt has been made in the laboratory to calibrate directly the spectrum "energy" for total air dose rate with a standard $\mathrm{Ra}^{226}$ source $^{2}$. Figure 5 is a plot of spectrum "energy" versus $\mathrm{Ra}^{226}$ dose rate in air and demonstrates the linearity of the response from 4 to $30 \mu \mathrm{r} / \mathrm{hr}$. The slope of this line is $54.0 \mathrm{BeV} / \mu \mathrm{r} / \mathrm{hr}$. This experiment was carried out, however, with the source placed along the symmetry axis of the crystal. A similar experiment was done with the source placed at various angles to the symmetry axis of the crystal to determine the crystal "energy" response to $\mathrm{Ra}^{226} \gamma$-rays as a function of angle (Figure 6). 
In the field situation, the $\gamma$-rays are entering the crystal from all angles, of course, although primarily from the ground half-space. As is well known, a calculation of the vector flux of photons above an interface for even a single monoenergetic source distributed uniformly in slab geometry is an extremely difficult problem. The angular distribution expected from primary photons for an infinite half-space geometry can be easily calculated (see Equation 5, p. 14). This distribution varies only slightly with energy (Figure 7), and indicates that most of the primary photons enter the crystal at fairly large angles with respect to its axis. We would not expect the scattered angular distribution to be very different although the peak of the distribution would probably be shifted to an even larger angle.

Figures 6 and 7 indicate that the angular correction factor of 0.82 which is required to reconcile the field calibration factor of 44.2 with the laboratory calibration factor of 54.0 is quite reasonable.

Analysis and discussion

The apparent linear relationship between the spectrum "energy" (which is essentially proportional to the photomultiplier light output for this energy region) and the actual air dose rate, and the consistency of the radium calibration with the field calibration, are reasonable based on the following considerations:

1. The well known non-airlike response of NaI at the lower energies is much less severe in a detector of the size used by us due to the increased relative efficiency for high energy events. This is illustrated by Figure 8 which shows the ratio of light output to air dose rate as a function of incident $\gamma$-ray energy for NaI crystals of thicknesses $1 \mathrm{~cm}$ and $10 \mathrm{~cm}$.

2. The low energy cutoff $(0.15 \mathrm{MeV})$ includes the energy range where most of the air dose is contributed, but not the region where the NaI response deviates most strongly from that of air. The dose rate contribution from the cerium isotopes (Table I) is neglected. This is generally on the order of a few tenths of a $\mu \mathrm{r} / \mathrm{hr}$ for typical fallout levels and probably partially

$?$ accounts for the small intercept of Figure 4 . Most of the natural dose rate is contributed by $\gamma$-rays in the 
energy region where the NaI/air relative response is fairly constant. For typical natural radiation fields only about $25 \%$ of the dose rate is delivered by photons of energy less than $0.3 \mathrm{MeV}$, while only about $5 \%$ is delivered by photons of energy above $2.5 \mathrm{MeV}$ (Figure 9 and reference 10).

3. The laboratory radium integral dose rate distribution is very similar to that resulting from natural sources in the field (see Figure 9). This is true since $\mathrm{Ra}^{226}$ and its daughters account for an appreciable proportion (approximately $20 \%^{3}$ ) of the terrestrial $\gamma$-ray dose rate in a typical situation, and the thorium series, another major contributor, has about the same average photon energy and a similar energy distribution. The increased number of lower energy scattered photons in the field is partially compensated for by the harder $\mathrm{K}^{40}$ spectrum.

4. The photon energy spectra encountered in the field vary over a limited range. Even under the "worst" conditions in terms of a radium calibration, that is, high fallout levels with a greatly increased lower energy component, no systematic deviations are observed in the total "energy" dose rates when compared to the dose rates obtained from the ion chamber. (Such deviations are often observed with survey instruments utilizing countrate meters.)

5. The integral distributions of spectrum "energy" actually obtained for a typical field location, a high fallout location, a low fallout location and the laboratory radium source are shown in Figure 10. These response spectra indicate that in all these cases only about $30 \%$ of the "energy" is between the low energy cutoff of the crystal and $0.4 \mathrm{MeV}$. Such response spectra are softer than the actual incident $\gamma$-ray spectra due to the loss of secondary photons from Compton scattering events in the crystal. Hence, the fraction of the dose rate contributed by $\gamma$-rays in the energy region where the relative response curve of Figure 8 varies even moderately from unity is probably less than $30 \%$.

6. Although the addition of fallout does soften the spectrum considerably, most of the dose rate from fallout is contributed by primary $\gamma$-rays, rather than $\gamma$-rays which are scattered in the ground. This is true because the 
fallout is usually distributed closer to the surface of the ground, resulting in a larger ratio of primary to total dose rate than would be obtained from a uniformly distributed source of the same energy. Since most of the fallout dose rate in our measurements was contributed by $\mathrm{Zr} 95-\mathrm{Nb} 95(0.75 \mathrm{MeV})$, the major $\gamma$-ray contribution was still in the region where the NaI-air relative response is close to unity. A large increase in or high relative contribution of fallout does, however, produce spectra quite a bit softer than that of the laboratory radium source (Figure 10, Curve D). It is quite clear, therefore, that the use of a radium calibration of the count rate rather than the total spectrum "energy" from a NaI detector would then result in a large overestimate in the dose rate due to the proportionally larger number of lower energy photons for the same dose rate.

7. The high energy cutoff at $3.4 \mathrm{MeV}$ includes essentially all events due to terrestrial $\gamma$-ray interactions in the crystal and renders negligible the energy contribution of cosmic radiation. We estimate that the sea level cosmic ray contribution to the spectrum "energy" is equivalent to a $\gamma$ response of $0.2 \mu \mathrm{r} / \mathrm{hr}$. This estimate is based on a spectrum obtained at an asbestos mine near Copperopolis, Calif., where the unusually low natural radioactivity of the serpentine bedrock itself resulted in a terrestrial $\gamma$-dose rate of only about $0.5 \mu \mathrm{r} / \mathrm{hr}^{5}$. This spectrum is shown in Figure 11. The dashed line is a log-log extrapolation back from the high energy portion of the spectrum and the integrated area under the dashed curve is $9.5 \mathrm{BeV} / 20 \mathrm{MIN}$. The altitude of this location was 700 feet. This nearly negligible cosmic ray response for the entrgy region in question is consistent with the results of Gustafson et. $a 1$.

Calculation of total dose rate

The total terrestrial dose rate at each survey location was thus obtained from the field spectra by summing the counts per channel multiplied by the mean $\gamma-r a y$ energy represented by that channel from $0.15 \mathrm{MeV}$ to $3.4 \mathrm{MeV}$, subtracting the small cosmic ray contribution and dividing the remainder by the semi-empirically obtained conversion 
factor of $44.2 \mathrm{BeV} / \mathrm{ur} / \mathrm{hr}$. This result was then compared with the terrestrial $\gamma$-ray dose rate predicted by the ionization chamber to obtain a "best value" for each location. 


\section{SPECTROMETRIC DETERMINATION OF COMPONENT DOSE RATE CONTRIBUTIONS - PEAK METHOD}

\section{Basic theory}

The three major naturally occurring contributors to the total terrestrial dose rate are $\mathrm{K}^{4 U}$ and the $\mathrm{U}^{238}$ and $\mathrm{Th}^{232}$ series. In addition to these natural emitters there are several prominent $\gamma$-emitting radioisotopes deposited in the upper layers of the soil by debris from nuclear weapons tests (see Table 1). Each of these emitters or series of emitters may be characterized by a single total absorption peak in our field spectra if the assumption of equilibrium among all the major gamma-emitting daughters in a given series is valid. Thus the $U^{238}$ series may be represented by the $1.76 \mathrm{MeV}$ peak of $\mathrm{Bi}^{214}$, and this peak area is an indication of the $\mathrm{U} 238$ daughter activity in the soil and therefore also the resultant dose rate contribution from the U238 series of $\gamma$-ray emitters. We have thus chosen the following prominent photopeaks of our field spectra to represent each of the major contributors to the total terrestrial dose rate; $2.62 \mathrm{MeV}$, Th232 series; $1.46 \mathrm{MeV}$, $\mathrm{K}^{40} ; 1.76 \mathrm{MeV}, \mathrm{U}^{238}$ series; $0.75 \mathrm{MeV}, \mathbf{Z r} 95-\mathrm{Nb}^{95} ; 0.51 \mathrm{MeV}$, $\mathrm{Ru} 106-\mathrm{Rh} 106$, Rul03-Rh103, Bal40-Lal40.

The dose rate contribution from each of these contributors may then be estimated using the formula

$$
\frac{N_{F}}{I}=\left(\frac{N_{O}}{\Phi}\right)\left(\frac{N_{F}}{N_{O}}\right)\left(\frac{\Phi}{I}\right)
$$

where $\mathrm{NF}$ is the estimated number of counts under the representative total. absorption peak of the field spectra, I is the dose rate in $\mu \mathrm{r} / \mathrm{hr},\left(\mathrm{N}_{O} / \Phi\right)$ is the number of counts obtained in the peak per unit primary flux incident along the crystal axis, $\left(\mathrm{N}_{\mathrm{F}} / \mathrm{N}_{\mathrm{O}}\right)$ is the ratio of peak counts in the field spectrum to the counts which would be obtained if the flux were incident along the crystal axis, and $(\Phi / I)$ is the primary flux expected per unit dose rate. 
Each of the factors in this equation can be determined for any crystal by a combination of experiment and theory for each of the emitters under discussion, and the product $\left(\mathrm{N}_{\mathrm{F}} / \mathrm{I}\right)$ is then divided into the estimated peak area to obtain the dose rate $I$.

\section{Estimate of peak area}

Due to the initial complexity of the primary $\gamma$-ray spectrum plus its subsequent degradation by scattering events in the source medium it is not easy to determine the true area of any given total absorption peak in the field spectra, i.e., the total counts under the peak. This is especially true of a peak such as that at $1.76 \mathrm{MeV}\left(\mathrm{Bi}^{214}\right)$, which lies on the side of the much larger $1.46 \mathrm{MeV}\left(\mathrm{K}^{40}\right)$ photopeak and is normally barely distinguishable from the continuum. We thus decided to use as a first estimate the area obtained by representing the continuum under the peak by a straight line on semi-log paper as shown in Figure 12 . The estimated area for each peak is taken to be the counts in the regions shown in the figure. These areas are assumed to be proportional to the true peak areas. (The choices of the particular regions shown in Figure 12 were arrived at primarily by trial and error procedures). This method minimizes the effects of gain variation in the detector system during and between measurements and probably only slightly underestimates the actual peak area. The method is of course not very precise, but as is shown later works very well. One of the primary reasons for its success is that the continuum upon which the photopeaks are resting changes shape relatively little from location to location. This appears to be true over the range of concentrations found for the major emitters. In addition, the large number of counts per unit dose rate in the $1.46 \mathrm{MeV}$ peak minimizes the impact of slight continuum variations on the $\mathrm{K}^{40}$ dose rate estimate. This is also true for the $0.75 \mathrm{MeV}$ Zr95-Nb95 peak. The 2.62. Tl208 peak is usually unaffected by other emitters and errors here are due more to poor statistics and difficulties in determining the continuum in a reproducible manner. The $\mathrm{Bi}^{214}$ peak at $1.76 \mathrm{MeV}$ is the one most affected by changes in other isotope activities and thus the U238 contribution is the least accurately determined by this method. 
Since our estimated peak area is only some proportion (hopefully constant) of the actual area of the peak, the laboratory calibrations necessary to obtain the first factor in Equation (1) must attempt to simulate the field situation in order to relate approximately the same proportion of peak area to incident flux. This was accomplished by utilizing the laboratory background spectrum whose continuum is quite similar to that obtained in typical field situations.

Determination of $(\mathrm{No} / \Phi)$

The factor $\left(\mathrm{N}_{\mathrm{O}} / \Phi\right)$ in Equation (1) can be obtained in the laboratory for the total absorption peaks characteristic of each of the major dose rate contributors through the use of suitable $\gamma$-ray calibration sources of known output. Table II lists the sources used in determining the response of our crystal as well as their half-lives and principal $\gamma$-ray energies.

For each of the sources listed in Table II the following experiment was carried out. The source was placed along the symmetry axis of the right circular cylindrical crystal and the distance $R$ from the center of the crystal to the source was varied to obtain different values of incident flux $\left(\gamma^{\prime} \mathrm{s} / \mathrm{cm}^{2}-\mathrm{sec}\right)$. The values of $R$ and source strength were chosen to provide a range of peak areas comparable to most of the peak areas in the field spectra for this particular energy region. In all cases $R$ was greater than 2 meters so that the $\gamma$-rays were essentially incident paraxially upon the crystal face. All measurements were taken without subtracting background to provide, as previously mentioned, a field-like continuum. In the case where a peak was already present in the laboratory spectrum, as with the three natural emitters, the background $l$ ab peak set a lower limit on the range of peak areas. The estimated peak areas, obtained in the manner discussed in the previous section, were then plotted against the known fluxes and the slope of the best straight line fit to these points was taken as $\left(\mathrm{N}_{0} / \Phi\right)$. In all cases these calibration curves turned out to be quite linear and the intercepts were (as expected) approximately equal to the estimated peak counts for the laboratory background peak (if any). Figures 13 and 14 are the calibration curves for the $\mathrm{K}^{42}$ and $\mathrm{Ra}^{224}$ sources. 
The values of $\left(\mathrm{N}_{\mathrm{O}} / \Phi\right)$ obtained separately for the 0.51 , 0.66 , and $0.75 \mathrm{MeV}$ peaks in the laboratory calibration are not strictly comparable to the field situation where all three peaks are present at the same time and overlap. However, interference experiments carried out using various combinations of $\mathrm{Sr}^{85}, \mathrm{Cs}^{137}$, and $\mathrm{Zr}^{95}-\mathrm{Nb}^{95}$ demonstrated that the method of estimating the 0.5 and $0.75 \mathrm{MeV}$ peaks shown in Figure 12 gives essentially the same value of $\left(\mathrm{N}_{O} / \Phi\right)$.

The value of $\left(\mathrm{N}_{\mathrm{O}} / \Phi\right)$ for the $1.76 \mathrm{MeV}$ peak ( $\mathrm{Bi}^{214}$ ) was inferred from the results obtained with the Sbl24 (1.69 MeV) source. The peak area was estimated as shown in Figure 12, since this particular approach provided data which showed the best correlation to Bi2l4 flux both for the field spectra (discussed under Energy Band Method) and for the laboratory calibration spectra, even though this is obviously a fairly large underestimate. In typical field spectra this estimated area usually contains on the order of 1000 counts and is quite sensitive to the analyser's determination of the $k^{40}$ peak area and continuum line. These relatively small peaks, as will be shown later, imply relatively small dose rate contributions from the $\mathrm{U}^{238}$ series and thus, although the percentage uncertainty in $\left(\mathrm{N}_{\mathrm{O}} / \Phi\right)$ may be large, the actual effect in terms of dose rate turns out to be quite small.

In order to determine the proportion of the actual total absorption peak included in our estimate of peak area, a rough total absorption peak efficiency curve was obtained for our 5" $x$ 3" crystal by using the data determined from the monoenergetic point source experiments with background subtracted. The absorption peaks were fitted to a gaussian and the resulting intrinsic peak efficiency (peak counts/total number of incidents $\gamma^{\prime} s$ ). compared with an efficiency curve for a 3" $x$ 3" crystal (Figure 15).

The values obtained for $\left(\mathrm{N}_{O} / \Phi\right)$ are given in Table III along with the corresponding total peak counts per unit flux based on Figure 15. In most cases our peak estimates appear to be about $80 \%$ of the actual peak area. 
Determination of $\left(\mathrm{N}_{\mathrm{F}} / \mathrm{N}_{\Omega}\right)$

The response of the crystal varies with the direction of the incoming flux due to such factors as varying absorption lengths, light collection properties, and solid angles subtended. This angular response was determined.for several energies by varying the angle between calibration source and crystal axis at $15^{\circ}$ intervals from 0 to $90^{\circ}$ keeping the source at a fixed distance. The estimated peak counts were then plotted versus angle of incidence. In all cases it was found that the resultant curve could be approximated to within a few percent by the equation

$$
N(\theta)=N(0) \cos [\alpha(E) \theta]
$$

The quantity $\left(\mathrm{N}_{F} / \mathrm{N}_{O}\right)$ is the ratio of peak counts actually obtained in the field to the number which would have been obtained if the crystal had no angular response, i.e., if $\cos \alpha \theta=1$. Thus,

$$
\left(\frac{N_{F}}{N_{O}}\right)=\frac{\int_{0}^{\frac{\pi}{2}} \frac{d \Phi}{d \theta} \cos \alpha \theta d \theta}{\Phi}
$$

where the incident primary flux is

$$
\begin{gathered}
\Phi=s \int d V \frac{e^{-x}}{4 \pi r^{2}}=\frac{s}{2 \mu_{t}(\operatorname{soil})}\left[e^{-t_{h}}-t_{h} E_{l}\left(t_{h}\right)\right] \\
x=\mu_{t}(\operatorname{soil})[r-h \sec \theta]+\mu_{t}(\text { air) }[h \sec \theta]
\end{gathered}
$$

assuming infinite slab geometry where $S$ is the emission rate for photons in $\gamma^{\prime} \mathrm{s} / \mathrm{cm}^{3}-\mathrm{sec}, \mu_{t}$ is the total absorption coefficient in $\mathrm{cm}^{-1}, \mathrm{~h}$ and $t_{h}$ are the height of the detector above the ground in units of $\mathrm{cm}$ and $\gamma$-ray mean free paths, 
respectively, and

$$
E_{I}\left(t_{h}\right) \equiv-E_{i}\left(-t_{h}\right)=\int_{t_{h}}^{\infty} \frac{e^{-u}}{u} d u
$$

The flux as a function of vertical angle is given by

$$
d \Phi=\frac{S}{2 \mu_{t}} \sin \theta e^{-t_{h} \sec \theta} d \theta
$$

Equation (3) thus becomes

$$
\left(\frac{N_{F}}{N_{0}}\right)=\frac{\int_{0}^{\frac{\pi}{2}} \sin \theta \cos \alpha \theta e^{-t_{h} \sec \theta} d \theta}{e^{-t_{h}}-t_{h} E_{l}\left(t_{h}\right)}
$$

The integral may be evaluated by expanding $\cos (\alpha \theta)$ in a Maclaurin series in terms of $\cos \theta$, i.e.:

$$
\begin{array}{r}
\cos \alpha \theta=\cos \alpha \frac{\pi}{2}+\alpha \sin \alpha \frac{\pi}{2} \cos \theta-\alpha^{2} \cos \alpha \frac{\pi}{2} \frac{\cos ^{2} \theta}{2 !} \\
+\left(\alpha-\alpha^{3}\right) \sin \alpha \frac{\pi}{2} \frac{\cos ^{3} \theta}{3 !}-
\end{array}
$$

The integral can then be evaluated easily since

$$
\begin{aligned}
& \int_{0}^{\frac{\pi}{2}} \sin \theta \cos ^{n} \theta e^{-t_{h}} \sec \theta d \theta=\int_{1}^{\infty} \frac{e^{-t_{h} u}}{u^{n+2}} d u \\
& \quad=-\left.\frac{1}{n+1} \frac{e^{-t_{h} u}}{u^{n+1}}\right|_{1} ^{\infty}-\frac{t_{h}}{n+1} \int_{1}^{\infty} \frac{e^{-t_{h} u}}{u^{n+1}} d u \frac{1}{t_{h}=0} \frac{1}{n+1}
\end{aligned}
$$


The result for $t_{h} \sim 0$ is sufficient since for 1 meter of air $t_{h}$ is on the order of $10^{-2}$. Thus we obtain

$$
\left(\frac{\mathrm{N}_{\mathrm{F}}}{\overline{\mathrm{N}}_{\mathrm{O}}}\right)=\cos \frac{\alpha \pi}{2}+\frac{\alpha}{2 !} \sin \frac{\alpha \pi}{2}-\frac{\alpha^{2}}{3 !} \cos \frac{\alpha \pi}{2}+\frac{\left(\alpha-\alpha^{3}\right)}{4 !} \sin \frac{\alpha \pi}{2}-\cdots
$$

The experimentally determined values of $\alpha$ and the calculated values for $\left(\mathrm{N}_{\mathrm{F}} / \mathrm{N}_{\mathrm{O}}\right)$ for several $\gamma$-ray energies are given in Table III.

These equations are for uniform source distributions. Similar calculations can also be carried out for plane or exponential source distributions, although the algebra becomes quite complicated. This was done for the case of the 0.5 and $0.75 \mathrm{MeV} \gamma$-rays and these values of $\left(\mathrm{N}_{\mathrm{F}} / \mathrm{N}_{O}\right)$ were found to vary very little from the uniform source distribution results (Table III).

Determination of $(\Phi / I)$

The first two factors in Equation (1) depend on the particular detector and thus must be determined by experiment. The ratio of incident primary $\gamma$-ray flux to total dose rate $(\Phi / I)$ for a given emitter or series of emitters is independent of the particular detector and depends mainly on the following parameters: source distribution, primary $\gamma$-ray energy, decay schemes of emitters, and degree of equilibrium among $\gamma$-emitting members of the $\mathrm{U}^{238}$ and $\mathrm{Th}^{232}$ series. All calculations are based on an. "infinite half-space" geometry and therefore all results are strictly applicable only to spectra obtained at locations approximating this situation. Since the crystal "sees" a fairly large area the survey site may vary quite substantially from the ideal geometry without affecting the results significantly. The differing source distributions for natural and fallout emitters lead us to consider each case separately.

\section{a. Natural Emitters}

The three major natural emitters are assumed to be distributed uniformly in the soil and the various members 
of the $\mathrm{U}^{238}$ series and $\mathrm{Th}^{232}$ series are assumed to be in equilibrium. The $1.76 \mathrm{MeV}, 2.62 \mathrm{MeV}$, and $1.46 \mathrm{MeV}$ primary $\gamma$-fluxes at 1 meter above the ground per $1 \mathrm{ppm} \mathrm{U} 238,1 \mathrm{ppm}$ Th 232 and $1 \%$ potassium soil concentration, respectively, are calculated using Equation (4).

The dose rates at 1 meter above the ground due to these concentrations of $\mathrm{U}^{238}, \mathrm{Th}^{232}$, and potassium can be calculated from theory using published decay schemes and approximate representations for the appropriate build-up factors to account for the effects of scattered photons. Such calculations have already been carried out for uniform concentrations of these three emitters and their daughters in equilibrium by Hultqvist ${ }^{15}$ and $0^{\prime}$ Brien et al ${ }^{16}$. The best values for I and $(\Phi / I)$ based on these calculations are given in Table IV.

It should be emphasized that the emitter concentrations for which the doses in the third line of Table IV are calculated refer to earth material in situ. Thus an increase in soil water will result in a lower dose rate for the same emitter concentration $\left(\gamma^{\prime} \mathrm{s} / \mathrm{cm}^{3}\right)$. The quantity $(\Phi / I)$, since $\Phi \sim\left(S / 2 \mu_{t}\right)$ (Equation 4$)$ and $I \sim\left(E_{O} / 2 p\right)^{16}$, where $E_{O}$ is the total energy emitted/ $\mathrm{cm}^{3}-\mathrm{sec}$ and $\rho$ is the soil density, varies roughly as $\rho / \mu_{t}$, and this quantity is relatively independent of material over the range of $\gamma$-emergies in question'7. Thus the validity of the dose rates inferred from Equation (1) should not be affected considerably by soil water content although natural emitter soil concentrations inferred from these dose rates may be somewhat in error. We have surveyed some sites where the soil water content was in excess of $30 \%$ by weight resulting in a substantially diminished dose rate contribution at that particular time. Generally the water content in the top layers of the soil is on the order of $10 \%$ by weight.

\section{b. Fallout Emitters}

The fallout emitters are assumed to be distributed in the soil according to the relation

$$
S=s_{o} e^{-a z} \quad \gamma^{\prime} s / \mathrm{cm}^{3}-\mathrm{sec}
$$


where $S_{0}$ is the emitter concentration at the surface and $z$ is the depth beneath the surface in $\mathrm{cm}$. Based on available soil data such a distribution, with $a=1 / 3 \mathrm{~cm}^{-1}$, appears to reasonably describe a typical situation ${ }^{2-22}$. The flux and total dose rate from a source distributed exponentially in this manner can be calculated from theory using the formalism of $\mathrm{O}^{\prime} \mathrm{Brien}$ et $\underline{\mathrm{l}}^{22}$ (see Appendix I). The results for $t_{h}=0$ are

$$
\begin{aligned}
& \Phi=\frac{s_{O}}{2 \mu_{t}} \frac{\ln (\delta+1)}{\delta} \quad \gamma^{\prime} \mathrm{s} / \mathrm{cm}^{2}-\mathrm{sec} \\
& I=\frac{s_{O}}{2 \rho} \frac{\mu_{e}}{\mu_{t}} \frac{E_{O}}{\delta}\left[\ln (\delta+1)+A_{O}-C_{O}\right] \mathrm{MeV} / \mathrm{gm}-\mathrm{sec}
\end{aligned}
$$

where $\rho$ is the density of air, $\delta=a / \mu_{t}$, $\mu_{e}$ is the energy absorption coefficient in air for the primary radiation in $\mathrm{cm}^{-1}, E_{O}$ is the energy of the $\gamma-r a y$ in $\mathrm{MeV}$, and $\mathrm{A}_{O}$ and $\mathrm{C}_{\mathrm{O}}$ are as given in Appendix 1. The ratios of primary flux to total dose rate (considering all the $\gamma$-rays emitted by the isotope or isotopes under consideration) may then be calculated for each of the major fallout contributors assuming various values of $a$ and using the appropriate decay schemes. These calculations were carried out for three cases: (1) $a=0$ (infinite half space), (2) $a \rightarrow \infty$ (plane source), (3) $a=1 / 3 \mathrm{~cm}^{-1}$. The results are given in Table $V$. Note that $(\Phi / I)$ is quite sensitive to depth distribution and changes significantly for only a slight penetration into the soil. Since the actual depth distribution of fallout emitters in soil depends strongly on the time since deposition (as well as other factors), the dose rate calibration factors for fallout will be considerably more uncertain than those for the natural emitters. The values of $(\Phi / I)$ for $a=1 / 3 \mathrm{~cm}^{-1}$ are used routinely for our measurements. Of course, any significant amount of fresh fallout would probably be better described by a plane source distribution. 


\section{Calculation of dose rates}

The estimated areas of the $0.75 \mathrm{MeV}, 1.46 \mathrm{MeV}, 1.76 \mathrm{MeV}$, and 2.62 MeV peaks, obtained as discussed previously, are divided by the appropriate calibration factors ( $N_{F} / I$ ) from Tables IV and $V$ to obtain estimates of the dose rate contributions from the emitters represented by these peaks.

Several radionuclides contribute to the $0.5 \mathrm{MeV}$ peak (Table V). Since the total dose rate per unit $0.5 \mathrm{MeV}$ flux depends on the decay scheme of the nuclide or series of nuclides under consideration, the dose rate calibration of the $0.5 \mathrm{MeV}$ peak area depends on the relative population of these nuclides, which in turn is a function of the mean age of the fallout (Appendix 2). Since $\mathrm{Rh} 106$ dominates the $0.5 \mathrm{MeV}$ activity for thermonuclear weapon fallout more than several months old and has an intermediate value for its peak calibration factor, its peak calibration and the exponential source distribution thus probably provides a reasonable estimate for the dose rate contribution of the $0.5 \mathrm{MeV}$ emitters in most circumstances.

The dose rate contribution of $\mathrm{Cs}^{137}$ (0.66 MeV) would be partially included with that of $\mathrm{Zr}^{95}-\mathrm{Nb}^{95}$ when the latter. is present in significant quantities, since the two peaks overlap in our spectra. The $0.66 \mathrm{MeV}$ peak is then generally completely hidden by the larger $0.75 \mathrm{MeV}$ peak. Other fallout emitters usually give only a very small proportion of the total dose rate.

\section{Limitations of peak method}

Although the peak area method is relatively crude and unsophisticated it will be shown to provide reasonably accurate dose rate estimates. The method has two distinct limitations. First, the precision of the results obtainable is lessened by the fact that personal judgement is involved in setting the continua to determine the peak areas. Second, the data analysis must for the most part be done by hand and thus the data from long survey trips require many man-hours of analysis. The peak method can, however, provide the 
basis for an improved method of estimating natural component dose rates utilizing a well-known "energy band" technique, described in the next section. 


\section{SPECTROMETRIC DETERMINATION OF COMPONENT DOSE RATE CONTRIBUTIONS - "ENERGY BAND" METHOD}

Basic theory

The disadvantages of the peak method can be eliminated by resorting to a well known "band" method of analyzing spectra (see, for example, refs. 23, 24). In this method the total "energy" (or counts) in the spectrum between energy values that bracket significant peaks is related to the dose rate contributions from the radiation that contributes to these peaks by means of simultaneous linear equations. The coefficients in these equations are usually determined by means of calibration sources using the same geometry as in the actual data analysis. In the case of spectra obtained in the field with half-space geometry it is not reasonably possible to obtain such calibration spectra and thus the coefficients must be inferred by other means.

Three such equations for determining the dose rates from $K^{40}$ and the $U^{238}$ and $T h^{232}$ series have been derived utilizing the dose rate results from the peak method and the results of a number of laboratory experiments. The development of these equations allows the computation of dose rates from the natural emitters by an IBM 1620 data processing system. The dose rates calculated from these equations agree closely with those obtained by the peak method, and are generally more precise.

\section{Energy bands}

Three bands were chosen to bracket the three total absorption peaks already calibrated, i.e.: from 1.32 to 1. $60 \mathrm{MeV}$ to include the $1.46 \mathrm{MeV} \mathrm{K}^{40}$ peak, from 1.62 to $1.90 \mathrm{MeV}$ to include the $1.76 \mathrm{MeV} \mathrm{Bi} 214$ peak, and from 2.48 to $2.75 \mathrm{MeV}$ to include the $2.62 \mathrm{MeV} \mathrm{Tl} 208$ peak. The energy calibration for each spectrum was determined as previously stated in section II. 
The response in each band is measured in terms of "energy" (as previously defined on page 3) for purposes of convenience in data analysis. The following equations are then assumed to be valid:

$$
\begin{aligned}
& E_{1}=u_{1} U+k_{1} K+t_{1} T+I_{1} \\
& E_{2}=u_{2} U+k_{2} K+t_{2} T+I_{2} \\
& E_{3}=t_{3} T+I_{3}
\end{aligned}
$$

where $E_{1}, E_{2}$, and $E_{3}$ are "energy"/20-minute counting period in bands 1,2 and 3 , respectively; $U, K$, and $T$ are the dose rates from the $\mathrm{U}^{238}$ series, $\mathrm{K}^{40}$ and the $\mathrm{Th}^{232}$ series, respectively; and the sets of constants $u_{i}, k_{i}$, and $t_{i}$ describe the distribution of spectrum "energy" per unit dose rate among these three particular energy bands. No provision is made in the above equations for fallout, since its contribution to these bands is usually negligible. The only important fallout radionuclides which emit gamma rays above $1 \mathrm{MeV}$ in any quantity are $\mathrm{Ba}^{140}-\mathrm{La}^{140}$ and $\mathrm{Sb}^{124}$ (see Table 1): Bal40-Lal40 has only occasionally appeared to make an important contribution, while the $1.7 \mathrm{MeV} \mathrm{Sb} 124$ $\gamma$-rays detected in spectra obtained during the Fall of 1962 and Spring of 1963 never contributed enough counts to significantly affect the validity of Equations (13), (14), and (15).

Since the highest energy $\gamma$-ray present in any quantity from either $\mathrm{K}^{40}$ or the $\mathrm{U}^{238}$ series is the 2.2. MeV Bi214 $\gamma$-ray, the contribution to the $\mathrm{E}_{3}$ band can be considered to be entirely from $2.62 \mathrm{MeV} \mathrm{Tl} 208 \gamma$-rays. The $1.46 \mathrm{MeV} \mathrm{K} 40$ $\gamma$-rays do contribute to the $E_{2}$ band, however, due to their presence in fairly large quantity and the relatively poor resolution of the crystal.

The cosmic ray contributions represented by $I_{1}, I_{2}, I_{3}$ can be considered constants, since the Copperopolis spectrum discussed on page 7 indicates that they are sufficiently small so that their variations with altitude can be considered negligible. 


\section{Dose rate equations}

Equations (13), (14), and (15) may be solved simultaneously for $U, K$, and $T$ :

$$
\begin{aligned}
& U=a E_{1}+b E_{2}+c E_{3}+d \\
& k=e E_{1}+f E_{2}+g E_{3}+h \\
& T=j E_{3}+1
\end{aligned}
$$

Each constant in these equations is some combination of the constants in Equations (13), (14), and (15). For instance the constant $a=k_{1} /\left[k_{1} u_{2}-k_{2} u_{1}\right]$. These equations, once the constants a-1 are determined, allow immediate calculations of the dose rates $U, K$, and $T$ for each spectrum. We shall consider each equation separately.

\section{a. Thorium Equation}

The constants in the equation for the thorium series dose rate may be determined using results from the peak method. The coefficient $t_{3}$ in Equation 15 is analogous to the quantity $\left(\mathrm{N}_{F} / I\right)$ of Equation (1), page 9, and can be determined in the same manner using the laboratory calibration spectra already obtained and computing $\left(E_{3} / \Phi\right)$ instead of $\left(\mathrm{N}_{O} / \Phi\right)$. The same values for $\left(\mathrm{N}_{\mathrm{F}} / \mathrm{N}_{O}\right)$ and $(\Phi / I)$ are used and the product then gives $\left(E_{3} / I\right)$. In this case however $T=\left(E_{3}-I_{3}\right) /\left(E_{3} / I\right)$ since the field spectra contain the constant cosmic ray contribution which is subtracted out in the laboratory calibration. $I_{3}$ was estimated to be at most $0.6 \mathrm{BeV}$ based on the Copperopolis spectrum. This value was adopted for use in Equation (1.5) and the final result was that Equation (18) was determined to be

$$
\mathrm{T}=.41 \mathrm{E}_{3}-.25 \mu \mathrm{r} / \mathrm{hr}
$$

The Th232 dose rates calculated from this equation are essentially identical to those obtained from the peak method except that individual determinations are more precise. 


\section{b. Potassium Equation}

The determination of $t_{3}$ was possible since we were dealing only with primary $2.62 \mathrm{MeV} \mathrm{Tl}^{208} \gamma$-rays. Similarly, since there are no $\gamma$-rays of energy greater than $1.46 \mathrm{MeV}$ from $k^{40}$ in the soil, $k_{1}$ and $k_{2}$ may also be gotten using the calibration data obtained with $\mathrm{K}^{42}$ standard. (Since the $\mathrm{K}^{42}$ peak is at $1.51 \mathrm{MeV}$ rather than $1.46 \mathrm{MeV}$ the $\mathrm{E}_{2}$ band was shifted over slightly for this calculation to place its center on the photopeak.) The values of $\mathrm{k}_{1}$ and $\mathrm{k}_{2}$ obtained were $9.8 \mathrm{BeV} / \mu \mathrm{r} / \mathrm{hr}$ and $0.80 \mathrm{BeV} / \mu \mathrm{r} / \mathrm{hr}$, respectively. The constants in Equation (17) depend, however, on the $u_{i}$ and $t_{i}$ also, and these coefficients cannot be determined in the laboratory since they are no longer dependent only on primary $\gamma$-rays but rather are quite sensitive to the scattering properties of the ground and air.

In order to determine Equation (17) fully, a multiple regression analysis was carried out for approximately 70 field spectra using the values of $K$ determined from the peak method. Fitting these sets of $\left(E_{1}, E_{2}, E_{3}, K\right)$ to Equation (17) resulted in the determination of a set of constares $(e, f, g, h)$ along with a value for the correlation coefficient. In the case of Equation (17) this correlation coefficient was very high (0.98) lending confidence to our assumption that our peak estimates were indeed proportional to dose rate. In addition, the coefficient $e$ which is equal to

$$
\mathrm{e}=: \frac{\mathrm{u}_{2}}{\mathrm{k}_{1} \mathrm{u}_{2}-\mathrm{k}_{2} \mathrm{u}_{1}} \doteq \frac{1}{\mathrm{k}_{1}}
$$

was determined from this analysis to be .10 $\mu \mathrm{r} / \mathrm{hr} / \mathrm{BeV}$ which compares very favorably with the value of $\mathrm{k}_{1}$ obtained above, thus also substantiating our peak area calibration factor. The final form of Equation (17) is:

$$
\mathbf{K}=.10 \mathrm{E}_{1}-.07 \mathrm{E}_{2}-.05 \mathrm{E}_{3}-.07 \mathrm{\mu r} / \mathrm{hr}
$$


The corresponding peak and band values of $K$ are again in excellent agreement on the average (as would be expected from the method of determining Equation (17a)). with the energy band values again providing slightly better precision.

\section{c. Uranium Equation}

A regression analysis was also applied to Equation (16), again using about 70 spectra. The correlation obtained here was poorer than that for Equation (17), due probably to the poor precision of the $\mathrm{U}^{238}$ peak area estimates and the small range of $U^{238}$ dose rates obtained in the field. Even poorer correlations resulted when other methods of estimating the $1.76 \mathrm{MeV}$ peak area were tried. The final equation adopted for $\mathrm{U}^{238}$ dose rate is

$$
\mathrm{U}=-.02 \mathrm{E}_{1}+.29 \mathrm{E}_{2}-.27 \mathrm{E}_{3}+.15 \mathrm{\mu r} / \mathrm{hr}
$$

The coefficient of $E_{2}$ in Equation (16a) cannot be directly compared to a calculated value such as was done in the case of Equation (17a) for $\mathrm{K}^{40}$. The reason for this is that in the field situation the $\mathrm{E}_{2}$ band contains a significant contribution from scattered photons from higher energy $\gamma$-rays of the uranium series. Experiments carried out using a Ra226 source showed that the increase in $\mathbf{E}_{2}$ per unit incident primary $1.76 \mathrm{MeV}$ flux was on the order of $25 \%$ when about 1.5 mean free paths of sand were placed between the source and detector. This result is consistent with the values for the coefficients of Equation (16a) obtained from the regression analysis and the value of $u_{2}$ obtained with the Ra226 source (in a manner similar to the determinations of $k_{1}$ and $t_{3}$ ) and indicates that Equation (16a) is reasonable.

Similar experiments with $T h 232$ sources demonstrate the definite effect on the coefficients of Equations (13), (14), and (15) of a large distributed scattering medium such as the ground and preclude the use of small laboratory calibration sources to even reasonably approximate these coefficients. 


\section{Applicability of dose rate equations}

The three equations (16a), (17a), and (18a) have been used by us to analyze several hundred spectra for $K^{40}$, $\mathrm{U} 238$ and $\mathrm{Th} 232$ dose rates, and the overall consistency of the results along with the independent verifications discussed in the next section lend support to their validity as well as to the validity of the peak method and its underlying calibrations and calculations. Although these equations refer only to our particular detector, the methods used to obtain them can similarly be applied to any large crystal. 


\section{VALIDITY OF DOSE RATE DETERMINATIONS}

\section{Consistency of data}

The $\gamma$ and cosmic radiation levels at the more than 200 locations surveyed in 1962 and 1963 encompassed a wide range of values, not only for the total dose rate but also for each of the individual natural and fallout contributors. At most of these sites the sum of the component dose rates obtained by the methods described herein agreed to better than $\pm 0.5 \mu \mathrm{r} / \mathrm{hr}$ with the total dose rate determined by our high pressure ionization chambers and total spectrum "energy" method. Table 6 presents the results from a representative sample of locations to illustrate this point.

The fallout dose rate in the table is calculated by two methods. In the first method the $\mathrm{Zr}^{95}-\mathrm{Nb} 95$ and $\mathrm{Ru} 106-\mathrm{Rh}^{106}$ dose rates computed from the peak areas are added to obtain the quantity called "F.O. (1)". The second method is to substract the total natural dose rate from the best value of the total terrestrial dose rate thus obtaining the value "F.O. (2)". In general, these two methods were found to agree very closely, substantiating the premise that $\mathrm{Zr}^{95}-\mathrm{Nb}^{95}\left(+\mathrm{Cs}^{137}\right)$ and $\mathrm{Rh}^{106}$ did contribute most of the fallout dose during these measurement periods and that our fallout calibrations are reasonably accurate. For the cases where agreement was not obtained, F.O. (1) was usually higher and the discrepancy could usually be explained by the presence of significant quantities of fresh fallout. As previously discussed the fallout calibration factors are quite sensitive to depth distribution, and fresh fallout, which would be better described by a plane source distribution, would result in an overestimate (Table V) using our exponential source distribution approximation.

Standard location measurements

Beginning in May, 1963, we attempted to monitor the changes in fallout $\gamma$ levels in the New York City area by 
repeated measurements at several locations. Three flat grassy areas in Westchester county, N. Y., were chosen, separated by about 5 miles from one another. The spectrometer indicated that the average natural $\gamma$ dose rates at the three locations were all approximately $7 / \mu \mathrm{r} / \mathrm{hr}$. The natural levels varied with time showing fluctuations as much as $\pm 20 \%$, probably due to changes in soil moisture, radon-222 migration and natural fallout. Such fluctuations in natural dose rate are not unusual ${ }^{35,26}$. Our best estimates of the fallout $\gamma$ levels at these sites are shown in Figure 16 . These data indicate that the fallout $\gamma$ levels in the New York area remained roughly constant at about $5 \mu \mathrm{r} / \mathrm{hr}$ from at least May to September 1963 and then decreased roughly exponentially with an apparent "half-life" slightly longer than that of Zr95-Nb95. This is consistent with the evidence provided by the field spectra that $\mathbf{Z r}^{95}-\mathrm{Nb} 95$ had been contributing $60-80 \%$ of the fallout dose rates during 1962 and 1963, the balance being attributed primarily to $\mathrm{Rh} 106$ and $\mathrm{Cs} 137$. The results of these standard location measurements offer strong support for the validity and usefulness of our method of analysis as well as indicating the degree of precision obtainable.

Intercomparison with field measurements by others

Adams et al $^{37}$ has developed a portable scintillation detection system for in situ determinations of $\mathrm{Th}^{232}$ soil concentrations. Figures 17 and 18 are based on data obtained by him at a number of our survey locations. Figure 17 is a plot of our 2.62 peak counts versus his determination of $\mathrm{Th}^{232}$ soil concentration. The solid line corresponds to our independent peak calibration factor (see Table IV), and the excellent fit demonstrates the validity of the assumptions involved in our peak method. Figure 18 is a plot of his soil concentrations versus our "energy" band Th232 dose rates. The solid line corresponds to the theoretical dose rate/p.p.m. conversion listed in Table IV. The agreement again is excellent and the decrease in scatter of individual points indicates the improvement in precision over the peak method. 
Intercomparison with laboratory soil sample analyses

In addition to the field intercomparisons of the preceding paragraph, soil samples have been taken at a number of our survey locations and analyzed by groups at Rice University, Argonne National Laboratory, and Lawrence Radiation Laboratory for $\mathrm{K}^{40}, \mathrm{Th}^{232}$ and $\mathrm{U}^{238}$ soil contents utilizing various laboratory spectrometric techniques $38,9,24$. The best values for Th232, potassium and $\mathrm{U} 238$ soil concentrations for each site are plotted against our "energy" band dose rate estimates in Figures 19, 20 and 21. The solid line in each case corresponds to the theoretical conversion factor of Table IV. The results of these analyses are for dry soil rather than in situ material and thus would in some cases be expected to be slightly higher than soil concentrations inferred from our dose rates using our theoretical conversion factors. Since our dose rate estimates are based on very large sample areas, the one to three $\mathrm{l} \mathrm{kg}$ soil samples obtained at each site are not necessarily representative of the area seen by the spectrometer. Thus the individual points of Figures 19, 20 and 21 exhibit quite a bit of scatter. In general, however, the potassium and $T h 232$ soil concentrations (Figures 19 and 20) are entirely consistent with our dose rate estimates and lend additional strong support to the validity of the $\mathrm{K}^{40}$ and $\mathrm{Th}^{232}$ dose rate predictions obtained by the peak and "energy" band methods.

Discussion of the $\mathrm{U}^{238}$ series intercomparison

In Figure 21 all the points fall above the line representing the theoretical U238 dose rate per p.p.m., i.e., all of the field spectra dose rates are low compared to the values predicted by the measured soil concentrations. This result is related to the fact that in the field situation part of the gaseous $\mathrm{Ra}^{226}$ daughter $\mathrm{Rn}^{22} 2$ escapes from the soil particles into the soil air. The $\mathrm{U}^{238}$ concentration data of Figure 21 are based on soil samples in which $\mathrm{Ra}^{226}-\mathrm{Rn}^{222}$ equilibrium had usually been restored before analysis. (Actually, these soil sample results really indicate $\mathrm{Ra}^{226}$ concentration rather than $\mathrm{U}^{238}$ concentration, 
since all determinations were by some form of $\gamma$ spectroscopy and $\mathrm{U}^{238}$ is quite likely not to be in equilibrium with $\mathrm{Ra}^{226}$ due to its greater tendency to leach from the upper soil layers during the soil-forming and weathering processes.) Since the principal emitters of $\gamma$-rays in the $U^{238}$ series are daughters of $\mathrm{Rn}^{222}$, the dose rate at 1 meter above the ground will be reduced according to the fraction of radon emanated from the soil particles into the soil air and subsequently lost to the atmosphere. The distribution of free radon in the soil air can be roughly described by onedimensional diffusion theory ${ }^{29}$. This theory predicts (steady state solution) an exponential distribution of radon with depth with a relaxation length depending on the half life and diffusion constant of the gas. (The Th232 daughter $\mathrm{Rn}^{220}$ is also a gas but its extremely short half life of 52 seconds reduces the effect of its movement in the soil to negligible proportions). Assuming a typical diffusion constant of $2 \times 10^{-2} \mathrm{~cm}^{2} / \mathrm{sec}^{29}$ and using the formalism of Appendix 1 we have calculated the the dose rate from such a distribution relative to the dose rate to be expected if this radon were distributed uniformly in the soil. This calculation indicates a reduction in dose rate of more than $90 \%$. Since other factors ${ }^{29}$ tend to reduce the radon content of the very top layers of soil even further, we can under normal conditions neglect the effect on the air dose rate of radon which has emanated from the soil, and consider the entire contribution of the $\mathrm{U}^{238}$ series to be from daughters of the radon which remain trapped in the soil particles. (Under normal conditions the radon daughters present in the atmosphere contribute only a few tenths of $\mu \mathrm{r} / \mathrm{hr}$ to the dose rate. This may not be the case, however, under conditions of temperature inversion when ground level air radon concentrations are known to build up to very high levels.)

One would not expect the emanating power of the soil to vary significantly with depth in the upper few inches of soil under most conditions, and thus this trapped radon will still be approximately represented by a uniformly distributed source and the peak calibration factor in Table IV will still be appropriate although the conversion 
from dose rate to $\mathrm{U}^{238} \mathrm{p} . \mathrm{p} . \mathrm{m}$. is no longer valid. Radon migration has been shown to be quite dependent on meteorological conditions ${ }^{29}$, however, and thus one would expect sizable variations in $\mathrm{U}^{238}$ dose rate with time ${ }^{25,26}$. Such variations have been apparent at our standard locations in Westchester county. Also the affect of "natural fallout", i.e., the deposition of airborne radon daughters on the surface of the ground primarily by rainfall, would cause additional variations with time in the $\mathrm{U}^{238}$ series dose rate. This would temporarily produce a non-uniform source distribution that would affect our inferred dose rate values ${ }^{30}$. Figure 21 indicates that the reduction in dose rate due to radon migration ranges roughly from $10 \%$ to $50 \%$. This result is consistent with published values for typical soil radon emanation coefficients ${ }^{30 / 31}$. (The emanation coefficient is defined as the ratio of radon which escapes into the soil air to the total radon produced, assuming $\mathrm{Ra}^{226}-\mathrm{Rn}^{222}$ equilibrium.)

Our dose rate estimates thus correspond to the equivalent $\mathrm{Ra}^{2} 26$ soil concentration of the trapped radon. The equivalent $\mathrm{Ra}_{2} 26$ soil content of the emanated radon can also be measured and the sum of these two values should then correspond to the equilibrium U $\mathrm{U}^{238}-\mathrm{Ra}^{226}$ soil content predicted by the soil sample analyses. One such measurement was carried out by Pearson ${ }^{32}$ (Univ. of Illinois) at one of our survey locations where soil samples had been obtained. The agreement obtained was excellent and suggested that further measurements of this type would be desirable.

The uncertainty in our $\mathrm{U}^{238}$ dose rate estimates is, of course, fairly considerable due to the factors discussed above (as well as the difficulties involved in the calibration); however, the discussion under Consistency of data suggests that this uncertainty is probably less than $\pm 20 \%$. Unfortunately, the small ratio of $\mathrm{U}^{238}$ dose rate to total natural dose rate $(\sim 20 \%)$ and also the limited range of $\mathrm{U}^{238}$ dose rates found at the locations surveyed thus far prevents a better estimate of the general validity of our U238 series calibrations. 
Total terrestrial $\gamma$ and cosmic ray dose rates

As previously discussed the high pressure ionization chamber measurements of total terrestrial dose rate, based on careful studies of the chamber's response to both $\gamma$-rays and cosmic rays, agree closely with the total dose rate obtained from the spectrometer over a wide range of altitudes. In addition these ionization chambers compare favorably with those of other investigators as well as with our own 20-liter air ionization chambers.

\section{Error estimates}

Based on the preceding discussions we conservatively estimate standard deviations for an individual determination of $\pm 10 \%$ for $\mathrm{Th}^{232}$ and $\mathrm{K}^{40}, \pm 20 \%$ for $\mathrm{U}^{238}$ and $\pm 0.5 \mu \mathrm{r} / \mathrm{hr}$ for total fallout for our individual component dose rate values, while $\pm 7 \%$ and $\pm 0.5 \mu \mathrm{r} / \mathrm{hr}$ would be reasonable uncertainties to assign to the total natural and total terrestrial $\gamma$ dose rate values, respectively. These error estimates are of course only informed guesses and include both the expected systematic uncertainties in the various calibration factors and experimental and statistical uncertainties of individual determinations. Among the experimental uncertainties is any error in the gain and zero calibration for each spectra. other factors which enter into the precision and accuracy of individual determinations would be fallout contributions to the three "energy" bands (primarily from the short-lived $\mathrm{Ba}^{140}-\mathrm{La}{ }^{140}$ ), large inhomogeneities in source distribution, poor geometry (large deviation from "infinite half space"), and the other problems already discussed in connection with the $\mathrm{U}^{238}$ and fallout dose rate estimates. Most of these factors are unconnected with the particular method of spectrum analysis used but rather are related to the impossibility of obtaining controlled laboratory-like experimental conditions in the field. Thus more refined and sophisticated methods of spectrum analysis, while possibly producing greater precision, would probably not result in any significant improvement in overall accuracy. 


\section{CONCLUSIONS}

In this report we demonstrate the feasibility and utility of applying unsophisticated methods of spectrum analysis to $\gamma$-ray spectrometric measurements obtained directly in the field with a large NaI(TI) crystal assembly. These field measurements can be obtained quite easily without any special modifications of standard pulse height analyzers and detectors available in most nuclear laboratories. The application of these methods requires only access to calibrated radioactive sources and some relatively straight-forward laboratory experiments to determine the response of the particular detector. The justification of the various approximations and assumptions involved in inferring dose rates from the spectra is based primarily on the overall consistency of the component and total dose rate results, the pattern of the standard location fallout variations, and the corroborating independent field thorium concentration measurements and laboratory soil sample analyses. Also, the natural dose rate estimates are reproducible within the limits of variation expected due to the many factors which cause the natural radiation field to vary with time (see Table 6). The precision of the results is sufficiently good to reflect and allow rough estimates of such variations. For instance, the April, 1964 Pelham, N. Y., measurement given in Table 6 was obtained when the soil was quite waterlogged due to several days of rainfall and both the $\mathrm{Th}^{232}$ and $\mathrm{K}^{40}$ dose rates were noticeably reduced. The $\mathrm{U}^{238}$ dose rate reduction was probably countered by the build-up of radon which can occur when the soil pores are filled with moisture.

The levels of accuracy and precision which can be obtained using these simple methods are quite sufficient for our particular interests in the field of environmental radiation. Dose rate estimates correct to within $\pm 10 \%$ are both necessary and sufficient for determining integrated population dose and the influence of fallout on population exposure, for studying differences in total and component 
dose rates from location to location, and for obtaining information on the relative contributions of the various components to the total $\gamma$ radiation field. Higher precision would of course be desirable for some related studies such as the detailed variation with time of total and component dose rates at a particular location.

The data accumulated in the past several years, in addition to providing us with valuable information on environmental $\gamma$ radiation at a large number of sites scattered throughout the United States ${ }^{3}$, has been used to provide realistic estimates (taking soil moisture and radon emanation into account) of typical potassium, $\mathrm{Th}^{232}$, and Ra226 contents of surficial soil4. Such data can also be useful in roughly inferring the mean age of deposited fission products (Appendix II).

The field measurements technique discussed in this report combines some of the advantages of both soil sampling and aerial surveys in that it provides considerable information for a relatively large sample volume. The source volume is large enough to greatly reduce potential difficulties associated with small-scale irregularities and anomalies in radioisotope distribution, while still providing sufficiently detailed spectra for important dosimetric inferences to be made. This consideration is particularly important where measurements representative of a much larger area are required. 


\section{ACKNOWLEDGEMENTS}

The $\mathrm{U}^{238}, \mathrm{~K}$, and $\mathrm{Th}^{232}$ soil concentration values supplied by J. A. S. Adams, Rice Univ.; P. Gustafson, Argonne National Lab.; A. Smith and H. Wollenberg, Lawrence Radiation Lab.; and L. Alexander, U. S Dept. of Agriculture were extremely valuable for demonstrating the validity and utility of our dose rate estimates.

The authors are indebted to N. Hallden, HASL, for preparing and accurately determining the activity of the $\gamma$-ray sources used for our various calibrations.

We are also indebted to J. E. McLaughlin, Director, Radiation Physics Division, for his encouragement and continued support, and who along with R. Sanna, K. O'Brien and $S$. Samson assisted in obtaining the mass of field data necessary to evaluate our techniques and equipment, as well as to $S$. Rothenberg for preparing the illustrations for publication, and $\mathrm{C}$. Metz and I. Hammerman, summer trainees, for their aid with some of the computations. 


\section{APPENDIX I \\ DOSE RATE FROM AN EXPONENTIALLY DISTRIBUTED SOURCE}

If we assume a source distribution $S(z)=S_{0} e^{-a z}$, then the dose rate at a height $h$ above the ground will be given by 2

$$
\begin{gathered}
I=\frac{s_{0} E_{0} \mu_{e}}{4 \pi \mu_{t} \rho}\left[\int_{t_{h}}^{\infty} \int_{0}^{\cos ^{-1} \frac{t_{h}}{t}} \int_{0}^{2 \pi} e^{-a / \mu_{t}\left(t \cos \theta-t_{h}\right)} e^{-t} b(t)\right. \\
\sin \theta d \Phi d \theta d t]
\end{gathered}
$$

where I is the dose rate in $\mathrm{MeV} / \mathrm{gm} / \mathrm{sec}$, $E_{O}$ is the energy of the primary gamma rays emitted, $\mu_{e}$ and $\rho$ the energy absorption coefficient and density of air, respectively, $\mu t$ the total attenuation coefficient of soil, $t=\mu_{t} r=$ number of mean free paths $\left(t_{h}=\mu_{t}(\right.$ air $\left.) \times h\right)$ and $b(t)$ is the dose rate buildup furition.

We shall use the representation of $b(t)$ given in reference 22 , i.e.,

$$
\begin{aligned}
& b(t)=(1+\alpha t)^{\beta}, \text { where } \alpha=\frac{1}{y}=\frac{\mu_{e}}{\mu t} \text { (soil) } \\
& \beta=\frac{\ln [y(y-1)+1]}{\ln (2)}, y<2.8 \\
& \beta=\frac{y-1}{\ln (2)}, \quad y>2.8
\end{aligned}
$$

Following the reference we expand $b(t)$ in a binomial series cutting off at $n$ terms where $n$ is the largest integer less than $\beta+2$. 


$$
b(t)=\sum_{i=0}^{n-i} \frac{t^{i}}{i !} B_{i}
$$

Integrating Equation (Al) over $\theta$ and $\Phi$ we obtain (letting $\left.\sigma=a / \mu_{t}\right)$

$$
\begin{aligned}
I= & \frac{s_{o} E_{o} \mu_{e}}{2 \rho \mu_{t}}\left[\int_{t_{h}}^{\infty} \frac{e^{-t}}{\sigma t}\left\{\sum_{i=0}^{n-1} \frac{t^{i}}{i !} B_{i}\right\} d t\right. \\
& \left.-e^{\sigma t h} \int_{t_{h}}^{\infty} \frac{e^{-(\sigma+1) t}}{\sigma t}\left\{\sum_{i=0}^{n-1} \frac{t^{i}}{i !} B_{i}\right\} d t\right]
\end{aligned}
$$

Separating out the $i=0$ terms we can rewrite (A4) as

$$
\begin{aligned}
I= & \frac{S_{0} E_{O} \mu_{e}}{2 \rho \mu_{t}}\left[\int_{t_{h}}^{\infty} \frac{B_{0} e^{-t}}{\sigma t} d t+\int_{t_{h}}^{\infty} \frac{e^{-t}}{\sigma} \sum_{i=1}^{n-1} \frac{t^{i-1}}{i !} B_{i} d t\right. \\
& \left.-e^{\sigma t_{h}} \int_{t_{h}}^{\infty} \frac{B_{0} e^{-(\sigma+1) t}}{\sigma t} d t-e^{\sigma t_{h}} \int_{t_{h}}^{\infty} \frac{e^{-(\sigma+1)}}{\sigma} \sum_{i=1}^{n-1} \frac{t^{i-1}}{i !} B_{i} d t\right]
\end{aligned}
$$

The first and third integrals may be evaluated immediately. Series solutions to the second and fourth integrals are assumed. The coefficients in these series may then be expressed in terms of the binomial coefficients in the expansion of $b(t)$. The solution to Equation (A5) is then

$$
\begin{aligned}
I=\frac{s_{0} E_{O}}{2 \sigma_{\rho}} & \frac{\mu_{e}}{\mu_{t}}\left[E_{1}\left(t_{h}\right)-e^{\sigma t_{h}} E_{1}\left\{(\sigma+1) t_{h}\right\}\right. \\
& \left.+e^{-t_{h}} \sum_{i=0}^{n-2} A_{i} \frac{t_{h}{ }^{i}}{i !}-e^{\sigma t_{h}} \sum_{i=0}^{n-2} \frac{(\sigma+1)^{i}}{i !} t_{h}{ }^{i} c_{i}\right]
\end{aligned}
$$


where

$$
A_{m}=\sum_{i=m+1}^{n-1} \frac{B_{i}}{i} \quad c_{m}=\sum_{i=m+1}^{n-1} \frac{B_{i}}{(\sigma+1)^{i}} \frac{1}{i}
$$

For $t_{h} \rightarrow 0$ it $c a n$ be shown using the series representation of $E_{1}(x)^{33}$ that $E_{l}\left(t_{h}\right)-e^{\sigma t_{h}} E_{l}\left\{(\sigma+l) t_{h}\right\} \rightarrow$ In $(\sigma+1)$ and we arrive at Equation (12) in the text. Equation (11) is obtained by letting $b(t)=1$, $i$. e., $A_{0}=C_{0}=1$. 


\section{APPENDIX II \\ FALLOUT AGE DETERMINATION}

The fact that the two prominent fallout peaks in the $\gamma$-ray energy spectra result from radioisotopes of quite different half-lives (see Table I) means that the ratio between the areas of the observed peaks is a strong function of the age of fission products. The $\mathrm{Zr}^{95-\mathrm{Nb} 95}$ peak at 0.75 $\mathrm{MeV}$, will increase with time as the $\mathrm{Nb}^{95}$ accumulates until about six months after formation and then decay with the 65 day half-life of the longer-lived $\mathrm{Zr}^{95}$. The $0.5 \mathrm{MeV}$ peak at first is quite large compared with the $0.75 \mathrm{MeV}$ peak because of the presence of the short-lived Bal40-Lal40 and $\mathrm{Ru} 103-\mathrm{Rh}^{103}$. As these decay away, the dominant contributor to this peak becomes Rul06-Rhl06, and thus the ratio of the $0.75 \mathrm{MeV}$ to the $0.5 \mathrm{MeV}$ peak increases at first and then decreases as the $\mathrm{Ru}^{106}-\mathrm{Rh}^{106}$ begins to dominate the spectrum. This phenomenon is shown in Figure 22, where the ratio between the measured peak areas in the field spectra is plotted against the age of the fallout. The data on fission yields for megaton weapons provided by Hallden et al $^{34}$ was used. If the yields for thermal fission are used instead the ratios become considerably higher, peaking at values near 20. This results from the dependence of the Rh106 concentration on the mode of fission, which limits the accuracy of the present method. The following assumptions were incorporated in the analysis: (1) the relative yields given in Reference (34) also apply to the ground deposition, i.e., no fractionation in transit; (2) the depth distribution in the ground of the various radioisotopes is exponential as described in the text. It can easily be seen that, except for the period between seven months and one year, the ratio of the peak areas is a relatively sensitive function of the mean age of the fallout. Such a method would be particularly useful as a means of quickly ascertaining the approximate age of newly deposited fallout since, if no other fallout is present initially, an estimate of the average age can be immediately determined from the ratio of the peak areas. 
If considerable fallout is already present, the mean age of fallout deposited between readings can be readily determined by simple subtractive techniques and corrections for decay.

The field spectra obtained during late 1962 and 1963 nearly all show peak ratios between 4 and 7 , with most falling between 5 and 6.5. This implies that we are dealing mostly with thermonuclear debris with mean ages for the deposited $\gamma$ emitters of from 6 to 13 months. The only locations where the observed peak ratios had values of less than 4 were those on the olympic peninsula surveyed in October 1962, which were also the only ones which exhibited large Lal40 peaks. Both of these indicators imply relatively recent fallout production and deposition, the fallout peak ratios corresponding to a mean age of 4 months. 
TABLE I

IMPORTANT FALLOUT $\gamma$ EMITTERS

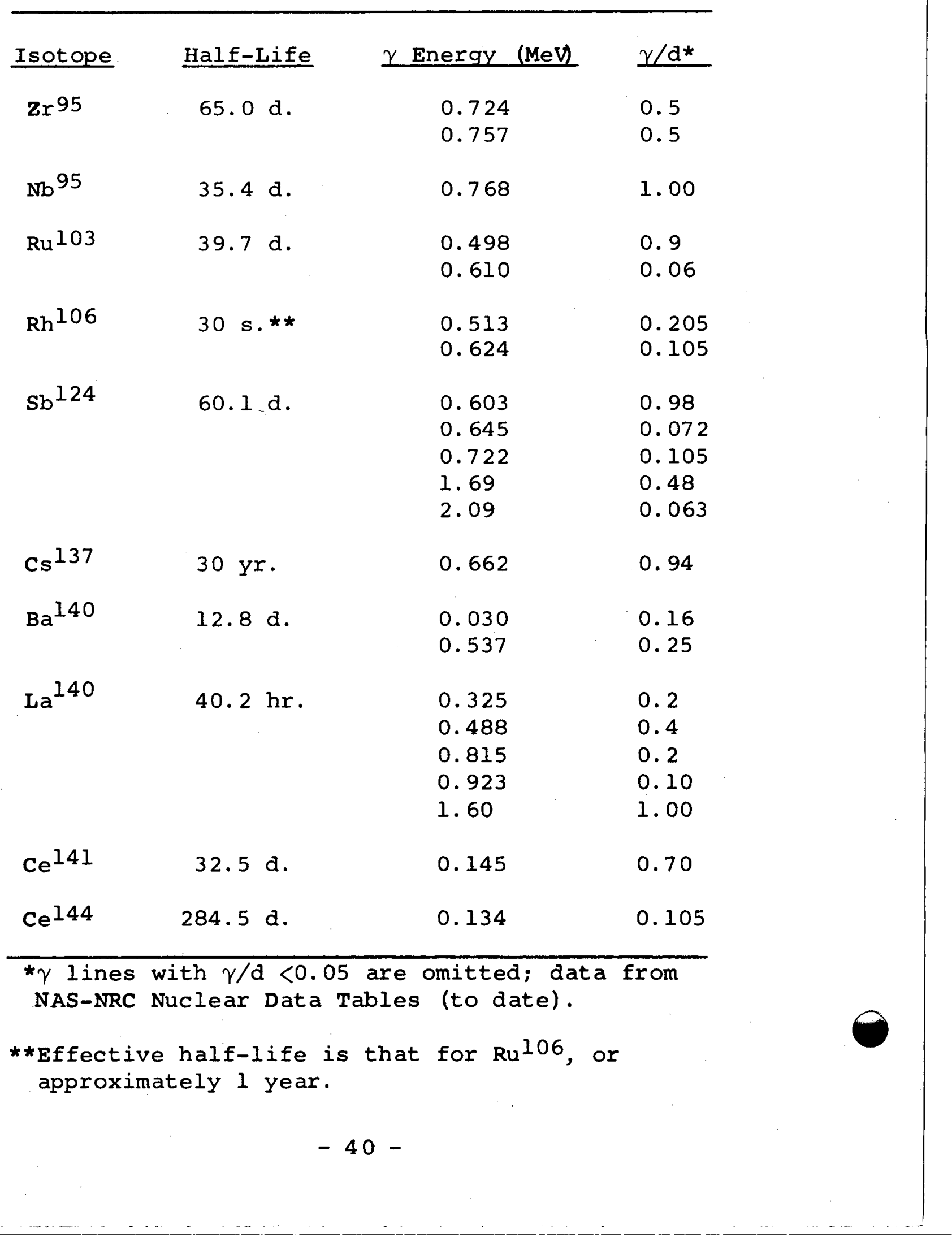




\section{TABLE II}

\begin{tabular}{lcc}
\hline & CALIBRATION SOURCES & \\
\hline \multicolumn{1}{c}{ Source } & \multicolumn{1}{c}{ Half-life } \\
Strontium-85 & 0.51 & $65 \mathrm{~d}$ \\
Cesium-137 & 0.66 & $30 \mathrm{y}$ \\
Zirconium- & & \\
Niobium-95 & 0.75 (average) & $65 \mathrm{~d}$ \\
Scandium-46 & $0.89,1.12$ & $84 \mathrm{~d}$ \\
Sodium-22 & $0.51 *, 1.28$ & $2.6 \mathrm{y}$ \\
Potassium-42 & $1.52 \quad 12.5 \mathrm{~h}$ \\
Antimony-124 & $0.60,1.69$ & $60.9 \mathrm{~d}$ \\
Radium-224 & $0.58,2.62$ etc. & $3.65 \mathrm{~d}$ \\
& & \\
\hline
\end{tabular}

*From annihilation of $\beta+$. 
TABLE III

\section{CALIBRATION OF NAI(TI) DETECTOR}

\begin{tabular}{|c|c|c|c|c|c|}
\hline Energy & $\left(\mathrm{N}_{\mathrm{O}} / \Phi\right)$ & $\begin{array}{l}\text { tual Peak } \\
\text { Unit Flux }\end{array}$ & rea) & $\alpha$ & $\left(\mathrm{N}_{\mathrm{F}} / \mathrm{N}_{\mathrm{O}}\right)$ \\
\hline .51 & 81000 & 85000 & & 0.60 & $0.80(0.78 *, 0.76 * *)$ \\
\hline .66 & 69000 & 76000 & & 0.59 & - \\
\hline .75 & 62000 & 69000 & & 0.53 & $0.83(0.80 *, 0.77 * *)$ \\
\hline .89 & 51000 & 61000 & & - & $-\quad \therefore$ \\
\hline 1.12 & 42000 & 50000 & & - & - \\
\hline 1.28 & 38000 & 45000 & & - & - \\
\hline 1.52 & 34000 & 40000 & & - & - \\
\hline 1.69 & 19000 & 36000 & & 0.46 & 0.87 \\
\hline 2.62 & 17000 & 26000 & : & 0.39 & 0.91 \\
\hline
\end{tabular}

*exponential source distribution

**plane source distribution 
TABLE IV

DOSE RATE CALIBRATION OF DETECTOR - NATURAL EMITTERS

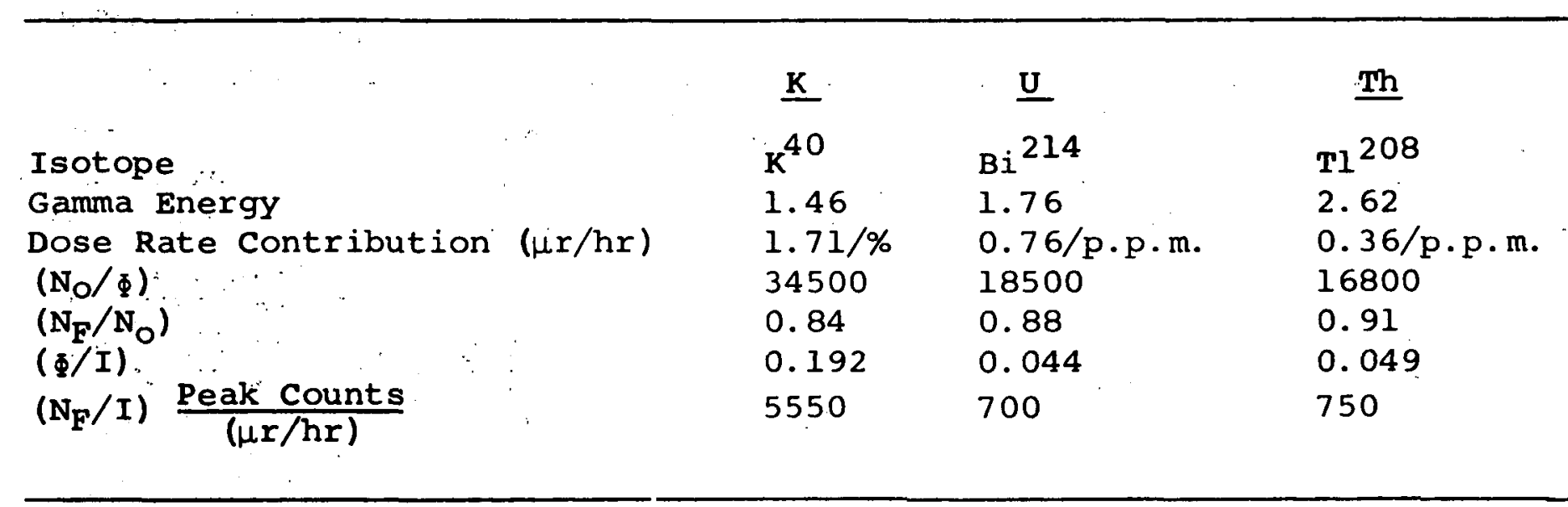


TABLE V

\section{DOSE RATE CALIBRATION OF DETECTOR - FALLOUT}

\begin{tabular}{|c|c|c|c|c|c|}
\hline Isotope & $\mathrm{Ba}^{140}-\mathrm{La}^{140}$ & $\mathrm{Ru}^{103}-\mathrm{Rh} \mathrm{h}^{103}$ & $\mathrm{Ru}^{106}-\mathrm{Rh}^{106}$ & $\mathrm{Cs}^{137}$ & $\mathbf{Z r}^{95}-\mathrm{Nb}{ }^{95}$ \\
\hline Gamma Energy & 0.49 & 0.50 & 0.52 & 0.66 & 0.75 (avg.) \\
\hline$\left(\mathrm{N}_{\mathrm{O}} / \Phi\right)$ & 81000 & 81000 & 81000 & 69000 & 62000 \\
\hline \multicolumn{6}{|l|}{$\left(\mathrm{N}_{\mathrm{F}} / \mathrm{N}_{\mathrm{O}}\right)$} \\
\hline half space & 0.80 & 0.80 & 0.80 & 0.82 & 0.83 \\
\hline exponential* & 0.78 & 0.78 & 0.78 & 0.79 & 0.80 \\
\hline plane & 0.76 & 0.76 & 0.76 & 0.77 & 0.77 \\
\hline \multicolumn{6}{|l|}{$(\Phi / I)$} \\
\hline half space & 0.06 & 0.34 & 0.18 & 0.29 & 0.26 \\
\hline $\begin{array}{l}\text { exponential* } \\
\text { plane }\end{array}$ & $\begin{array}{l}0.10 \\
0.14\end{array}$ & $\begin{array}{l}0.55 \\
0.77\end{array}$ & $\begin{array}{l}0.29 \\
0.40\end{array}$ & $\begin{array}{l}0.45 \\
0.60\end{array}$ & $\begin{array}{l}0.41 \\
0.54\end{array}$ \\
\hline \multicolumn{6}{|l|}{$\left(\mathrm{N}_{\mathrm{F}} / \mathrm{I}\right) \quad \frac{\text { Peak Counts }}{(\mu \mathrm{h} / \mathrm{hr})}$} \\
\hline half space & 3900 & 22000 & 11500 & 16400 & 13500 \\
\hline exponential* & 6300 & 35000 & 18500 & 24500 & 21000 \\
\hline plane & 8600 & 47500 & 24500 & 32000 & 28000 \\
\hline
\end{tabular}

*Assuming $s=$ So $e^{-0.33 Z}$ 
TABLE VI

REPRESENTATIVE SURVEY RESULTS

\begin{tabular}{|c|c|c|c|c|c|c|c|c|c|}
\hline \multirow[t]{3}{*}{ Town } & \multirow[t]{3}{*}{ Date } & \multicolumn{8}{|c|}{ Dose Rates $(\mu r / h r)$} \\
\hline & & \multicolumn{2}{|c|}{ Total $x$} & \multicolumn{3}{|c|}{ Natural $\gamma$} & \multicolumn{2}{|c|}{ Fallout $\gamma$} & \multirow[t]{2}{*}{ Cosmic Ray } \\
\hline & & Ion. Ch. & Spect. & $\underline{\mathbf{K}}$ & $\underline{\mathrm{U}}$ & Th & F.0.(1) & F.0.(2) & \\
\hline Memphis, Tenn. & $(4 / 63)$ & 11.8 & 11.2 & 1.8 & 1.7 & 2.7 & 5.0 & 5.3 & 3.5 \\
\hline Lake Chas., La. & $(4 / 63)$ & 8.4 & 8.6 & 0.7 & 0.9 & 1.9 & 5.2 & 5.0 & 3.4 \\
\hline Bonnydoon, calif. & $\begin{array}{l}(10 / 62) \\
(10 / 63)\end{array}$ & $\begin{array}{l}13.6 \\
12.8\end{array}$ & $\begin{array}{l}13.4 \\
12.7\end{array}$ & $\begin{array}{l}8.5 \\
7.7\end{array}$ & $\begin{array}{l}2.2 \\
2.5\end{array}$ & $\begin{array}{l}1.9 \\
1.5\end{array}$ & $\begin{array}{l}1.8 \\
1.2\end{array}$ & $\begin{array}{l}0.9 \\
1.0\end{array}$ & $\begin{array}{l}4.0 \\
4.0\end{array}$ \\
\hline Denver, Colo. & $(10 / 63)$ & 16.3 & 15.4 & 4.0 & 2.5 & 8.7 & 0.6 & 0.6 & 6.3 \\
\hline Clallam Bay, Wash. & $(10 / 62)$ & - & 5.3 & 1.0 & 1.3 & 0.4 & 2.8 & 2.6 & 3.6 \\
\hline Pelham, New York & $\begin{array}{l}(5 / 63) \\
(6 / 63) \\
(10 / 63) \\
(4 / 64)\end{array}$ & $\begin{array}{r}12.4 \\
12.0 \\
9.2 \\
7.8\end{array}$ & $\begin{array}{r}12.4 \\
12.2 \\
9.3 \\
7.9\end{array}$ & $\begin{array}{l}2.9 \\
2.5 \\
2.3 \\
2.1\end{array}$ & $\begin{array}{l}1.0 \\
1.2 \\
1.2 \\
1.3\end{array}$ & $\begin{array}{l}3.3 \\
3.4 \\
3.4 \\
2.6\end{array}$ & $\begin{array}{l}4.9 \\
4.8 \\
2.3 \\
1.5\end{array}$ & $\begin{array}{l}5.1 \\
5.1 \\
2.4 \\
1.8\end{array}$ & $\begin{array}{l}3.5 \\
3.5 \\
3.5 \\
3.5\end{array}$ \\
\hline
\end{tabular}




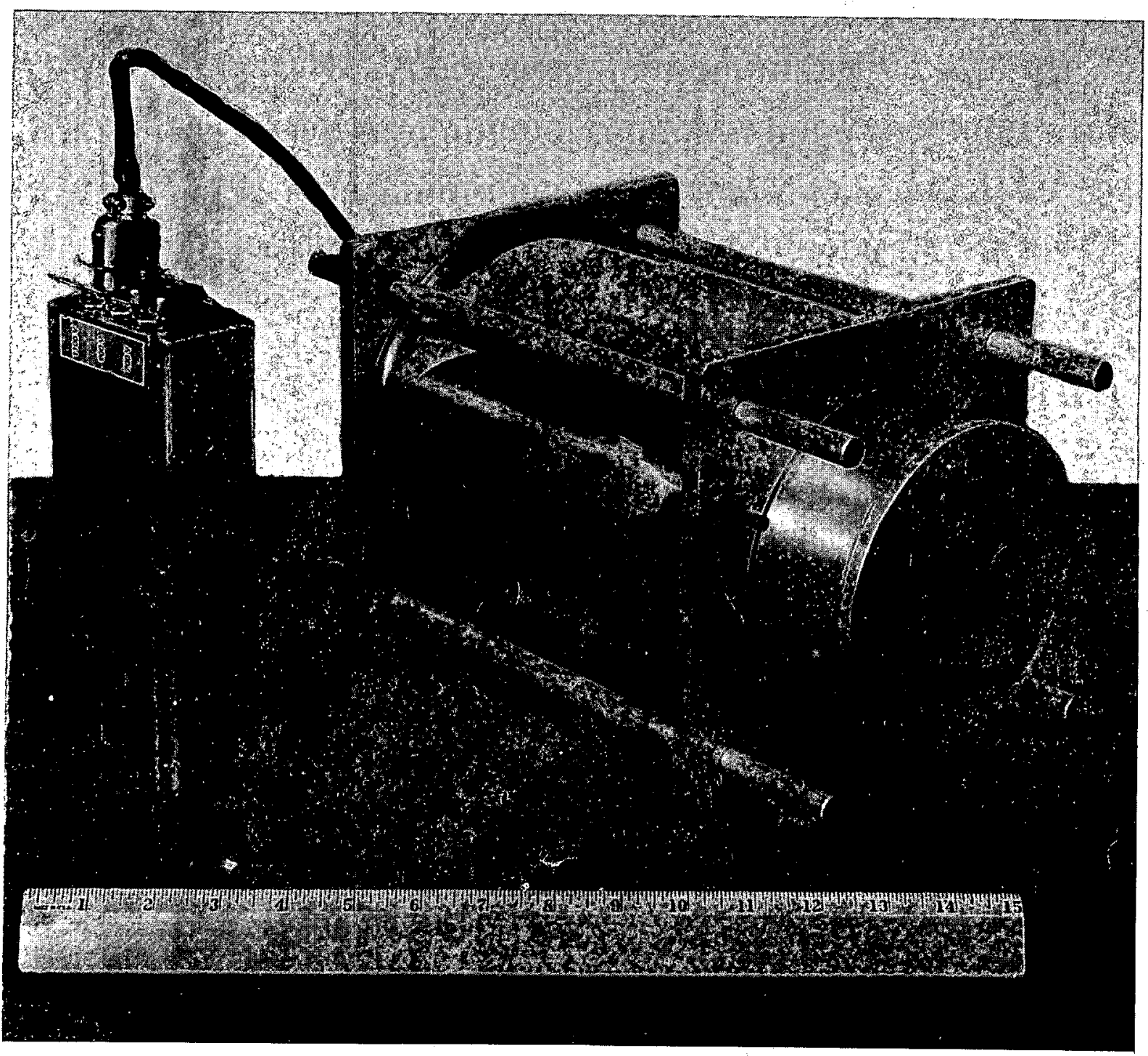

Figure 1. Detector assembly and battery pack. 


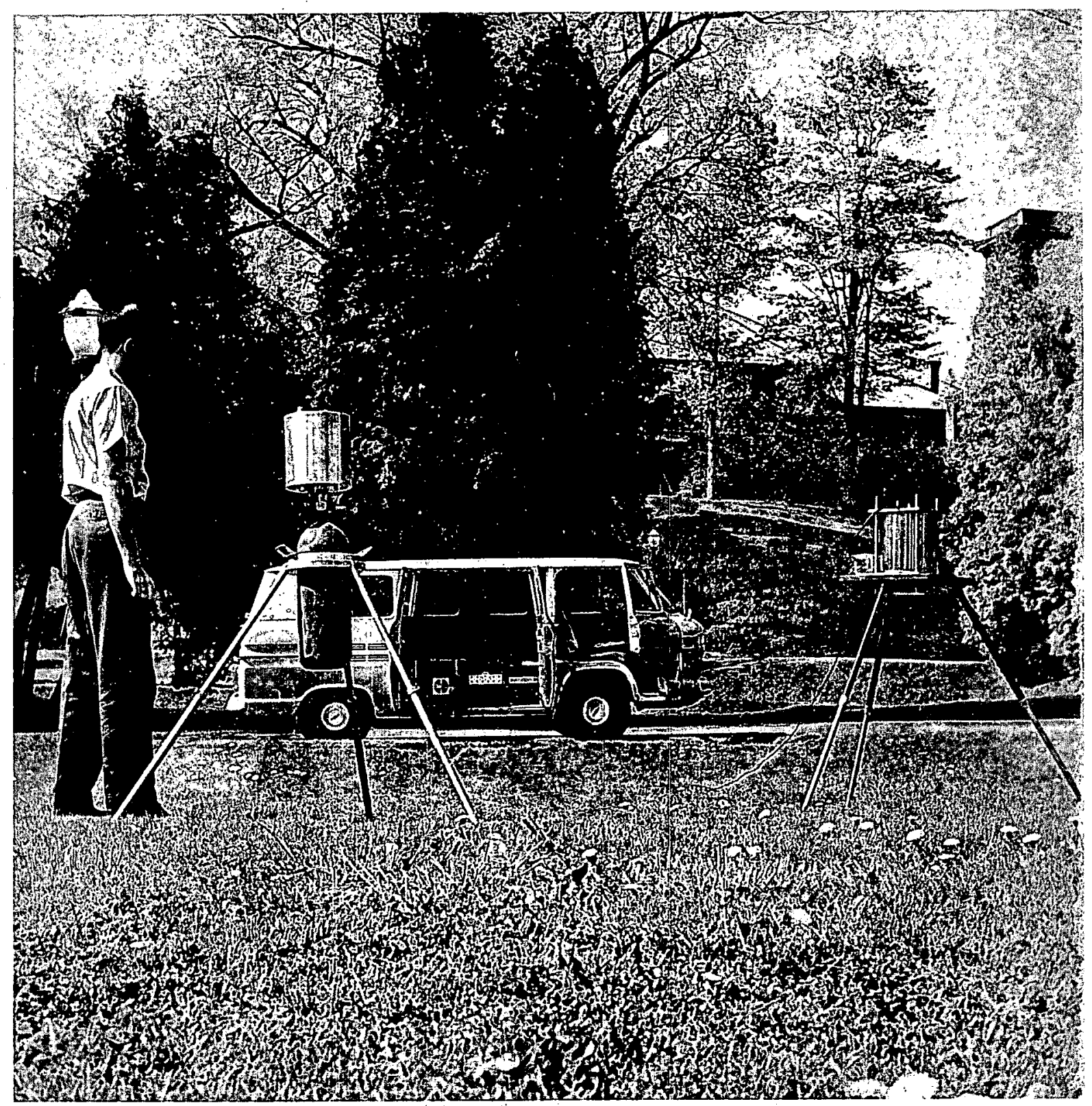

Figure 2. "The HASL pressurized ionization chamber and spectrometer set up for a typical measurement. Saratoga Springs, N. Y., 1963. 


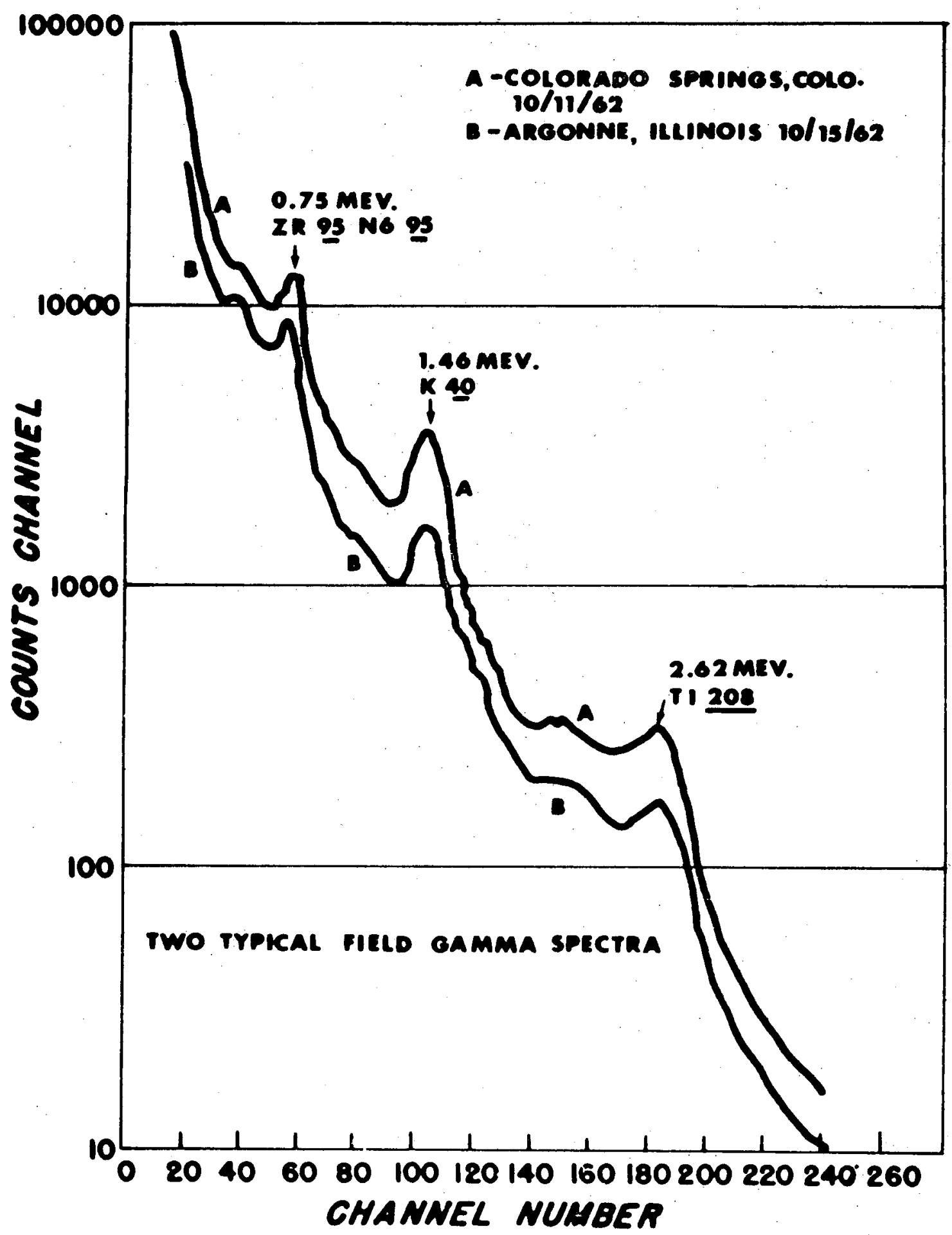

Figure 3. Two typical field spectra obtained during late 1962. The cosmic, natural $\gamma$, and fallout $\gamma$ levels are all somewhat higher at location A. 


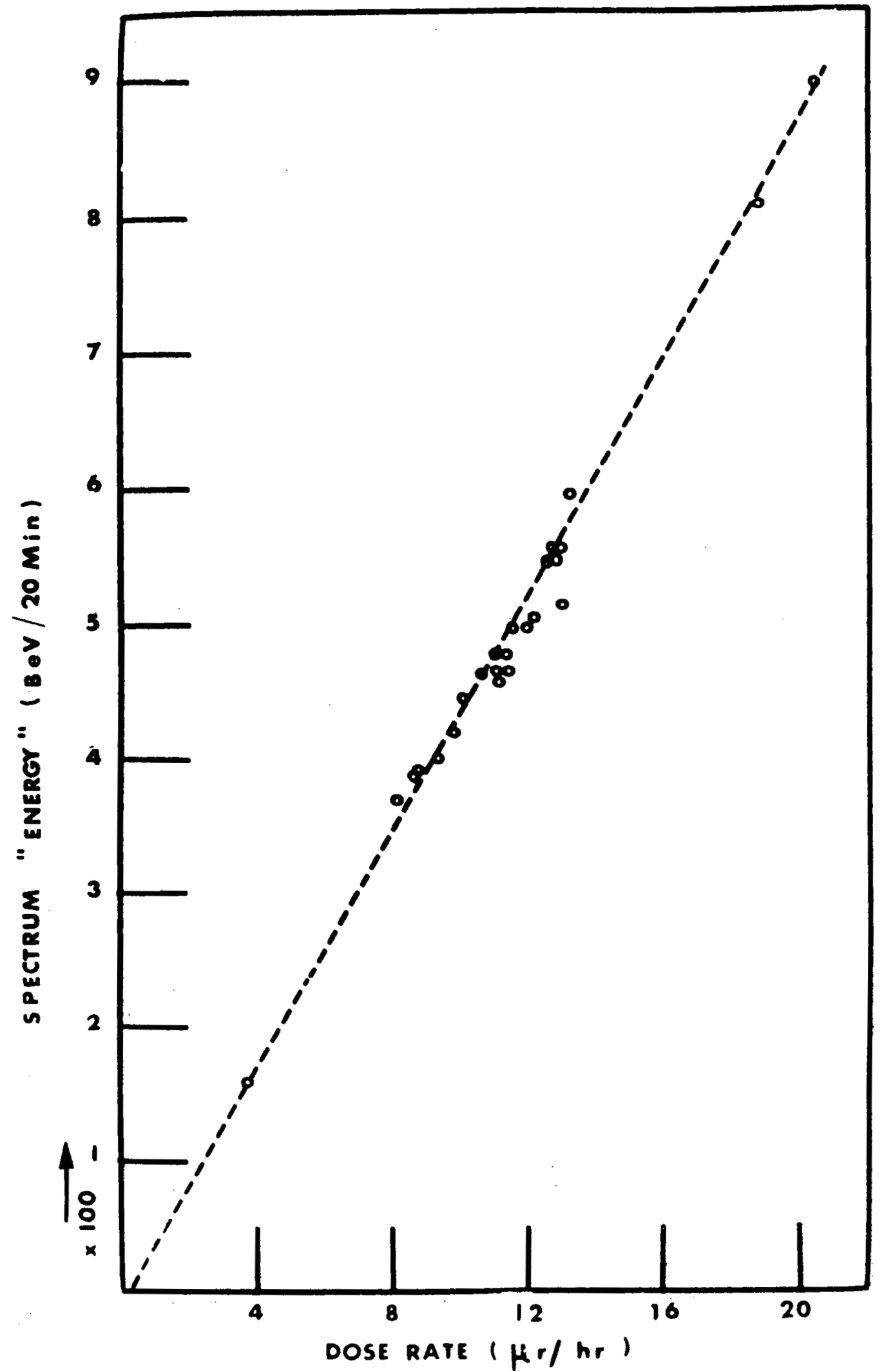

- Figure 4. Spectrum "energy" at a number of locations surveyed in April, 1963 vs, ionization chamber terrestrial dose rate. The small intercept is probably real and results from a cel44 contribution below the low energy cutoof of $0.15 \mathrm{MeV}$.

$$
-49-
$$




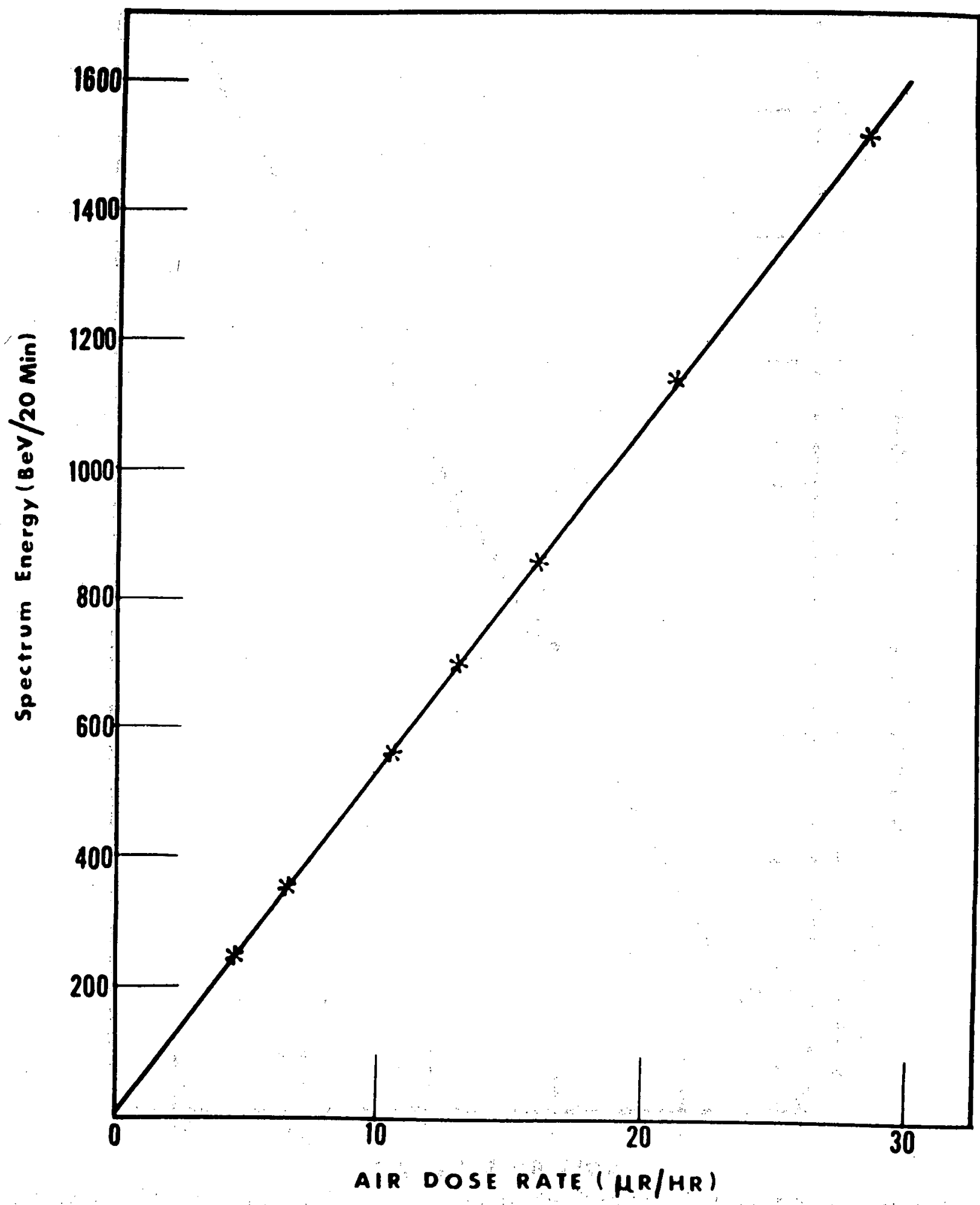

Figure 5. Spectrum "energy" as a function of air dose rate produced by $\mathrm{Ra}^{226}$ source in laboratory. 


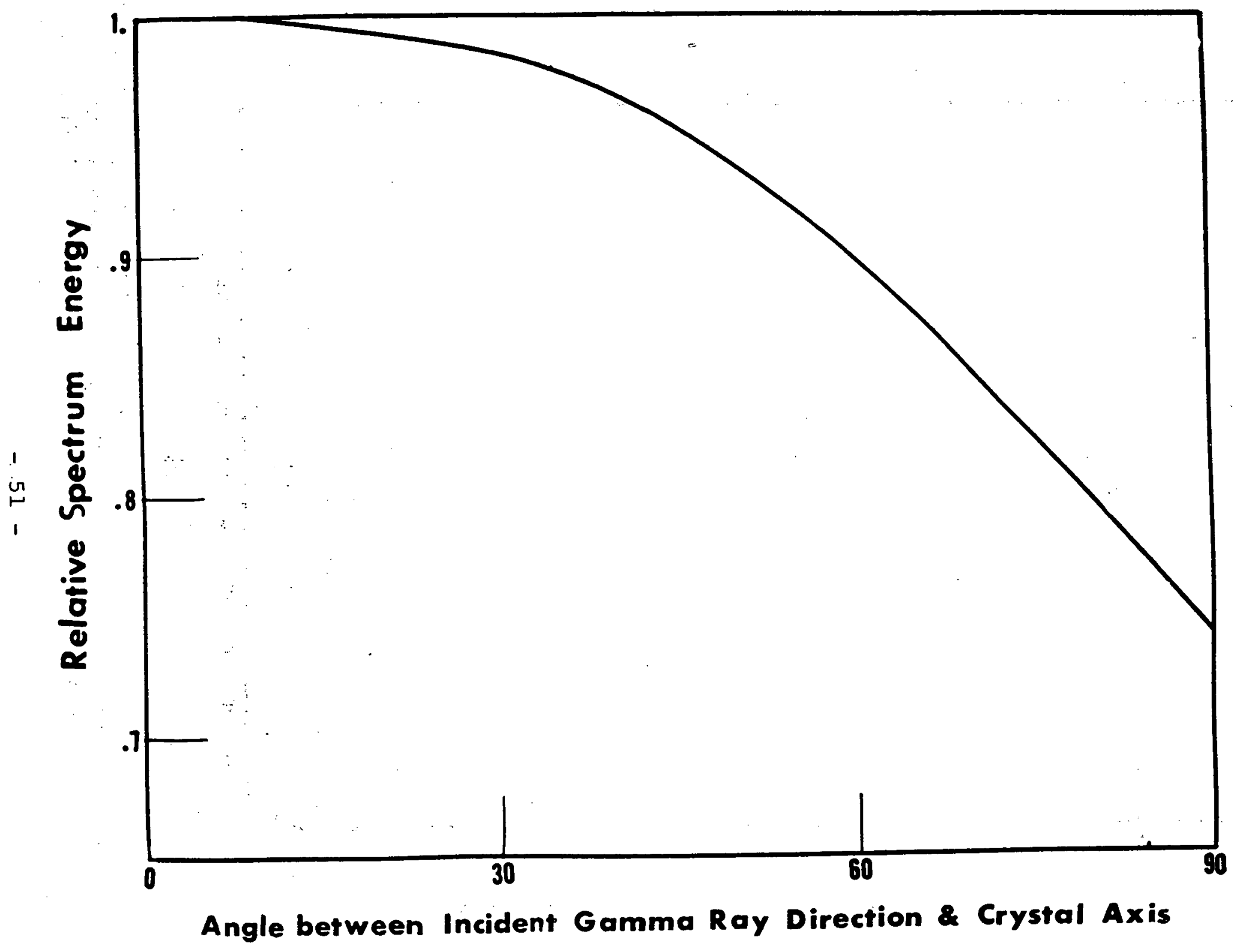

Figure 6. Angular response of detector to $\mathrm{Ra}^{226}$ source. 


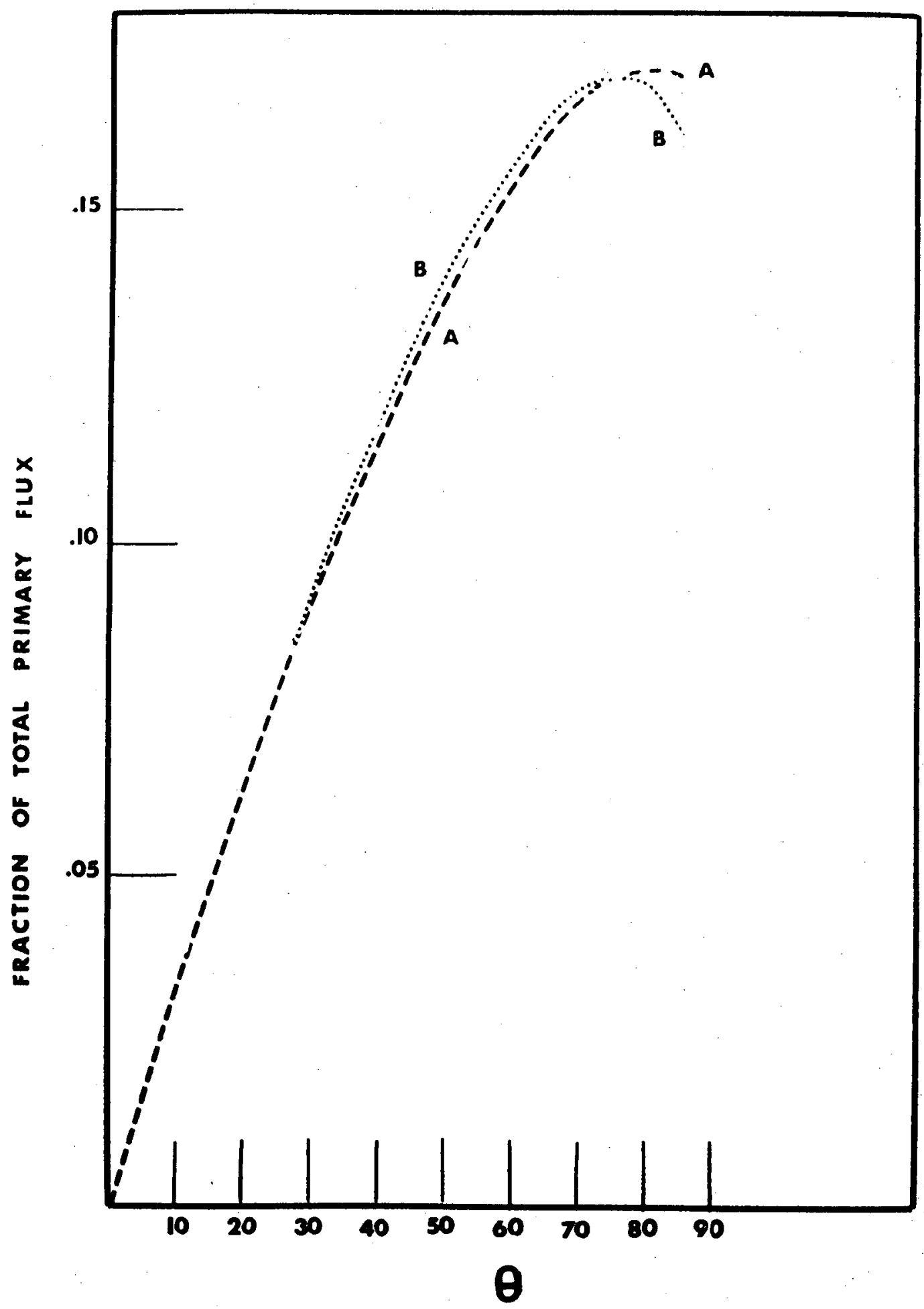

Figure 7. Fraction of total primary $\gamma$-ray flux from the ground halfspace incident on detector at angles of $\theta \pm 5^{\circ}$ to the crystal axis. (Curve A) is for $3.0 \mathrm{MeV}$ photons and (curve $\bar{B}$ ) is for $0.5 \mathrm{MeV}$ photons. 


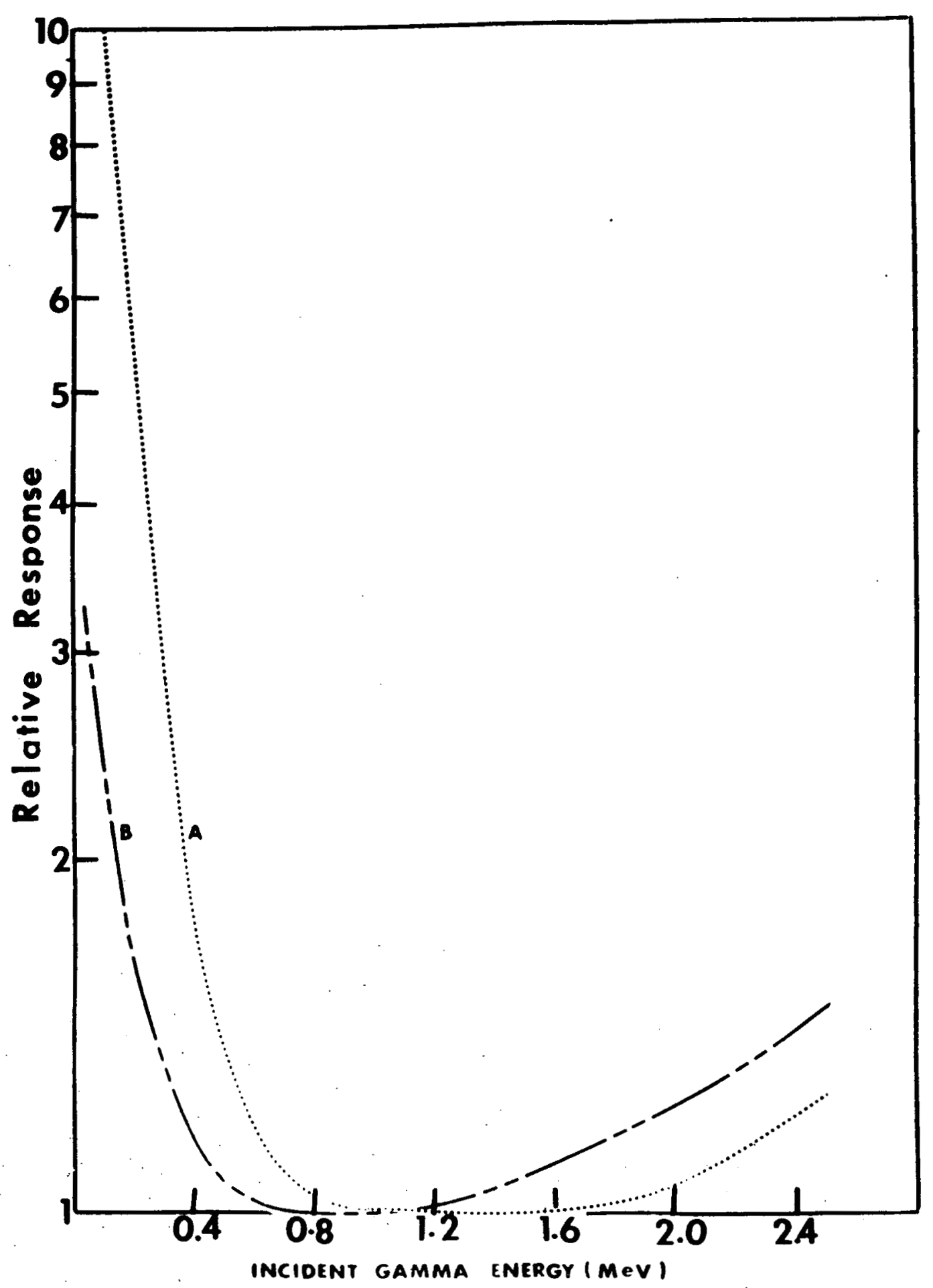

Figure 8. Ratio of NaI(Tl) light output to air dose rate (normalized to unity at $\mathrm{l} \mathrm{MeV}$ ) as a function of incident $\gamma$-ray energy for $\mathrm{NaI}$ (Tl) crystals of thickness $1 \mathrm{~cm}$. (curve A) and $10 \mathrm{~cm}$. (curve B). Curves are based on graphs and equations given in reference 12 . 


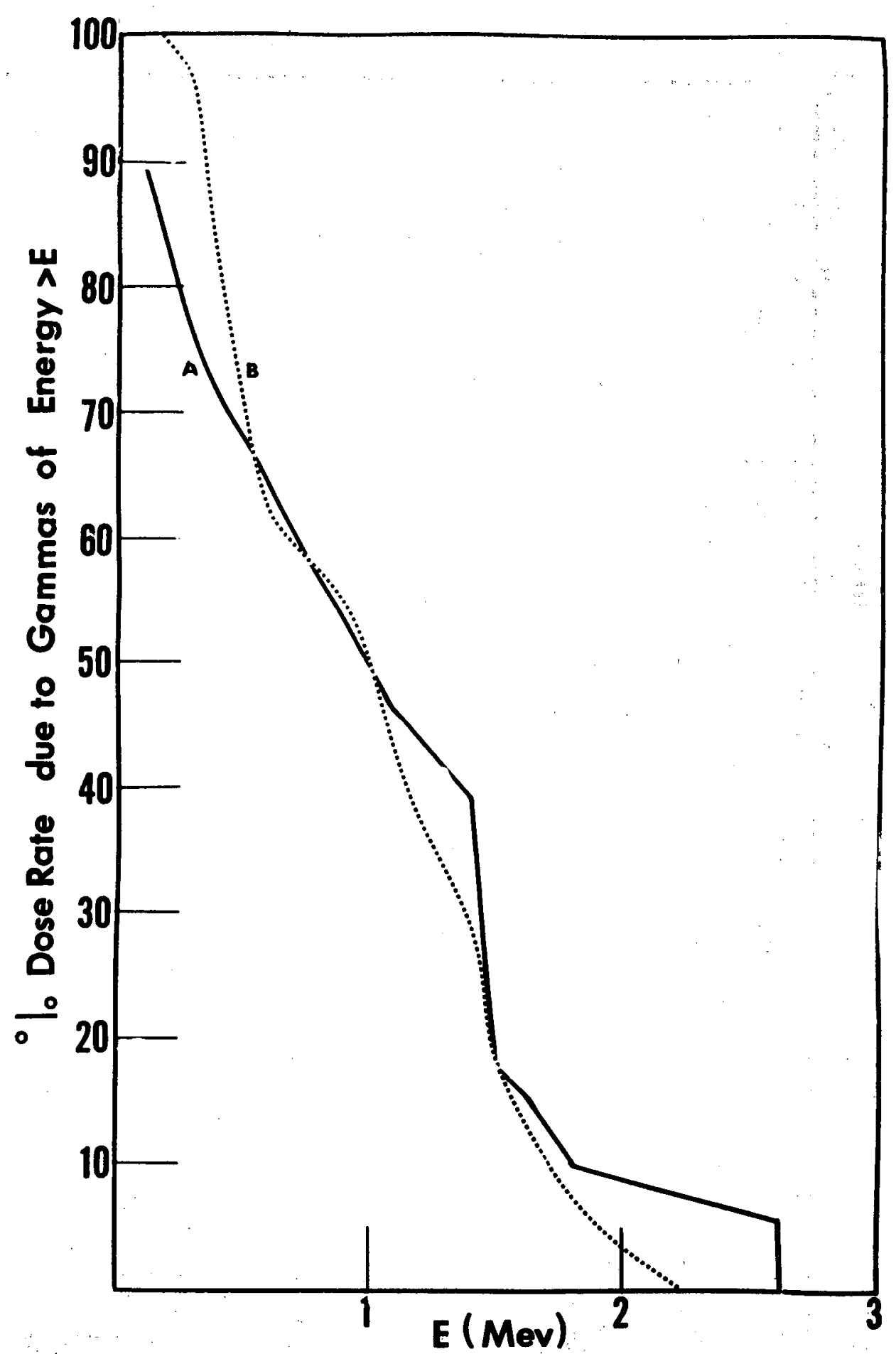

Figure 9. Integral $\gamma$-ray dose rate distribution resulting from the ground half-space (curve A) and from a Ra226 point source (curve B). Curve. A is based on the calculations of Gates and Eisenhower as discussed in reference 10, assuming a typical situation in which $\mathrm{K}^{40}$ and the $T^{232}$ series each contribute $40 \%$ of total dose rate and the $\mathrm{U}^{238}$ series the remaining $20 \%^{3}$. Curve $\mathrm{B}$ is based on data given in reference 11 . 


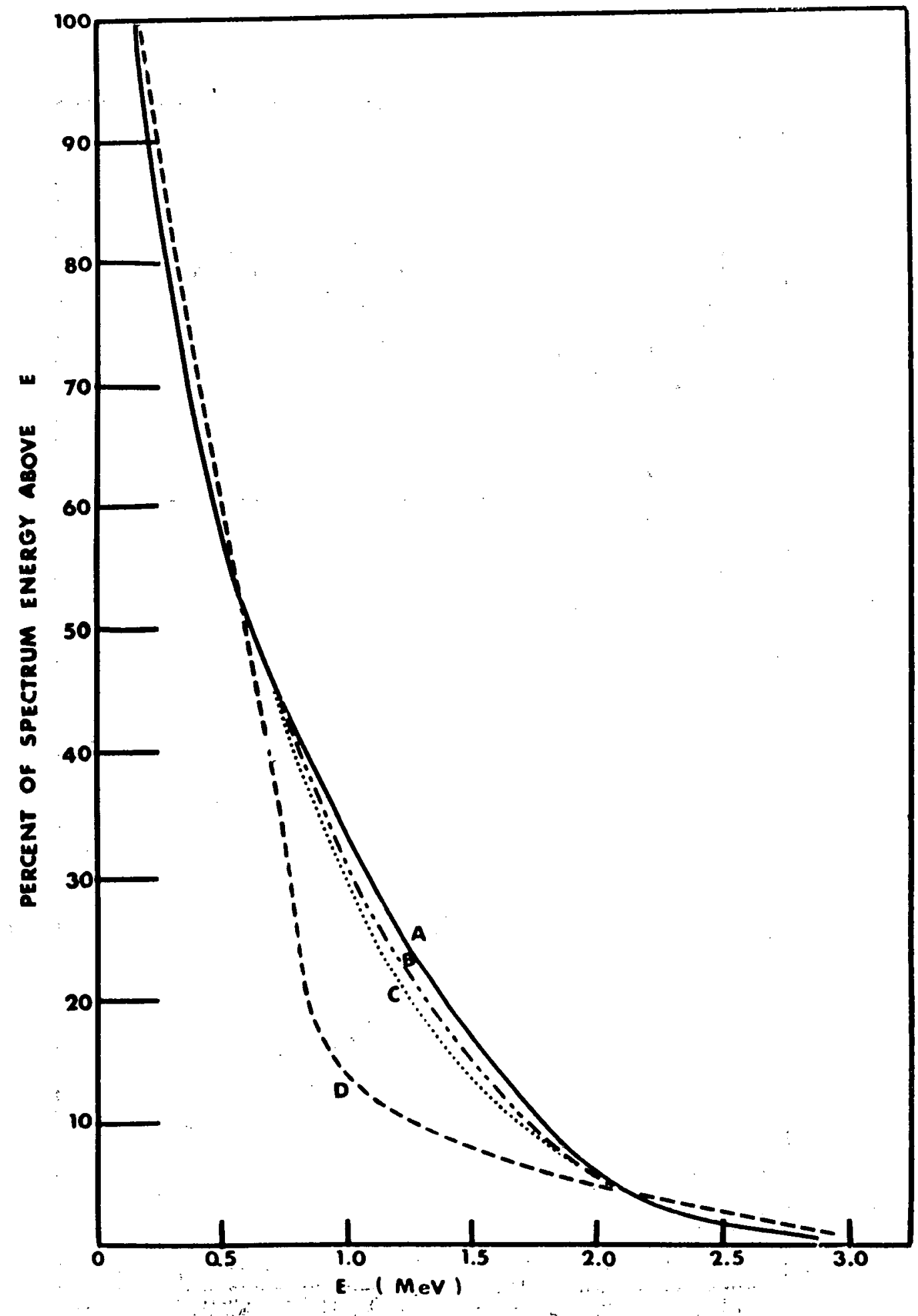

Figure 10. Integral distributions of spectrum "energy" for 3 field spectra (curves $B, C, D$ ) and a spectrüm from a Ra226 point source in the laboratory (curve A). $E$ is the incident $\gamma$-ray energy. Spectrum $B$ was obtained at a location where fallout contributed less than $20 \%$ of the total $\gamma$ dose rate; while curves $C$ and $D$. correspond to locations where fallout contributed $34 \%$ and $65 \%$ of the total $\gamma$ dose rate, respectively. 


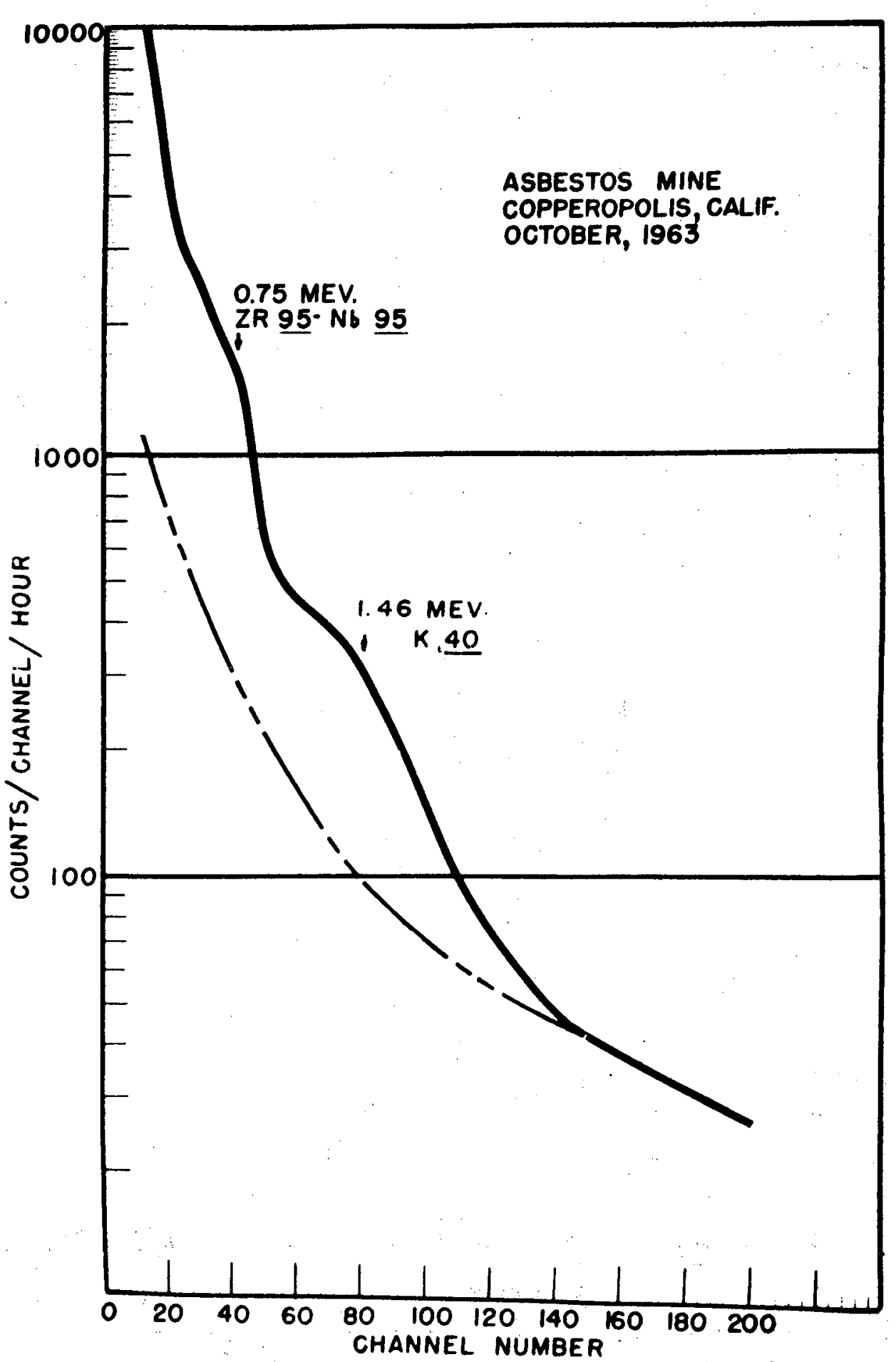

Figure 11. Field spectrum obtained over freshly exposed serpentine at asbestos mine near Copperopolis, California. This spectrum was accumulated in approximately one hour of live time as opposed to the twenty minute live times for the spectra of Figure 3 . 


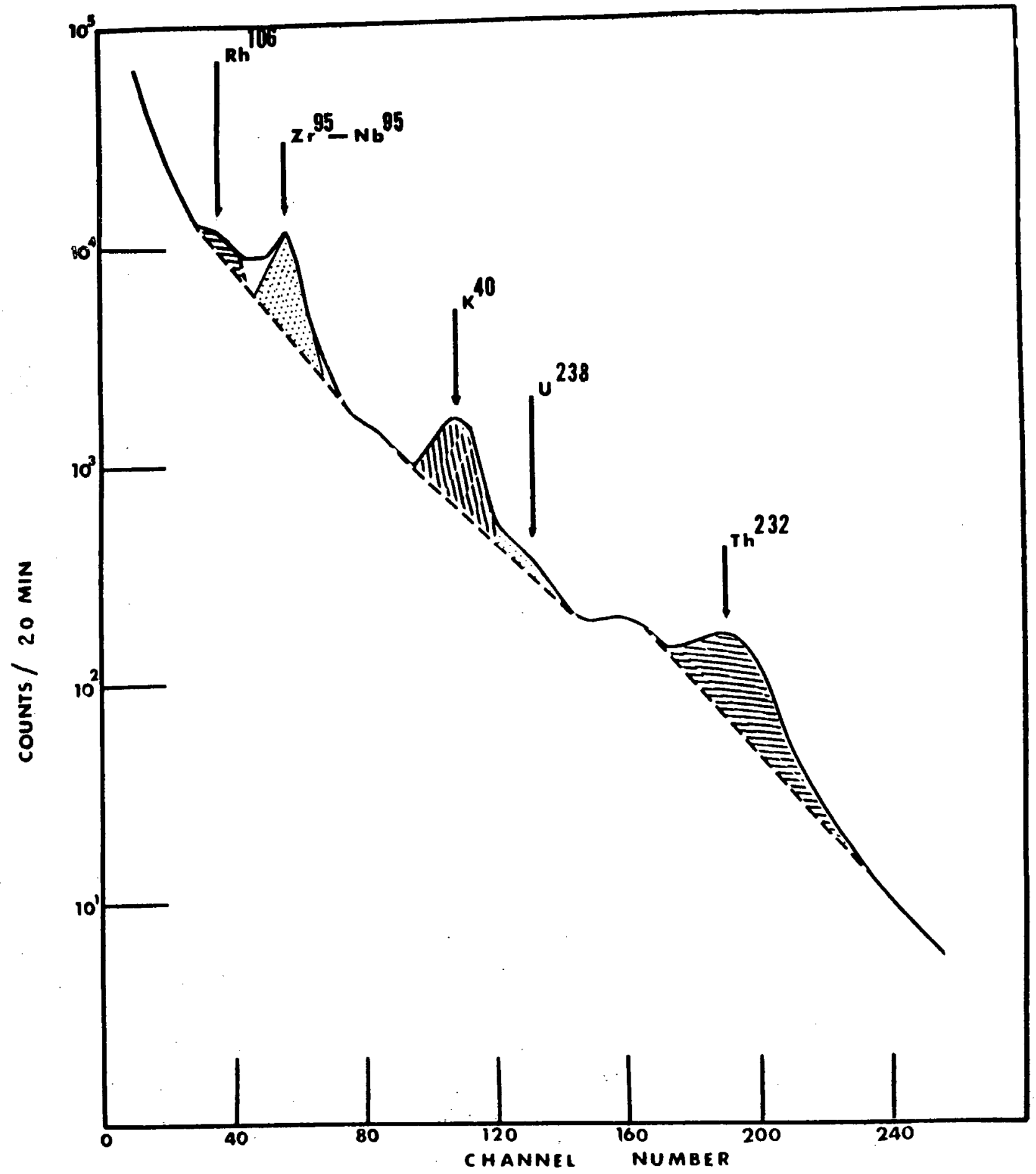

Figure 12. Absorption peak area estimates. 


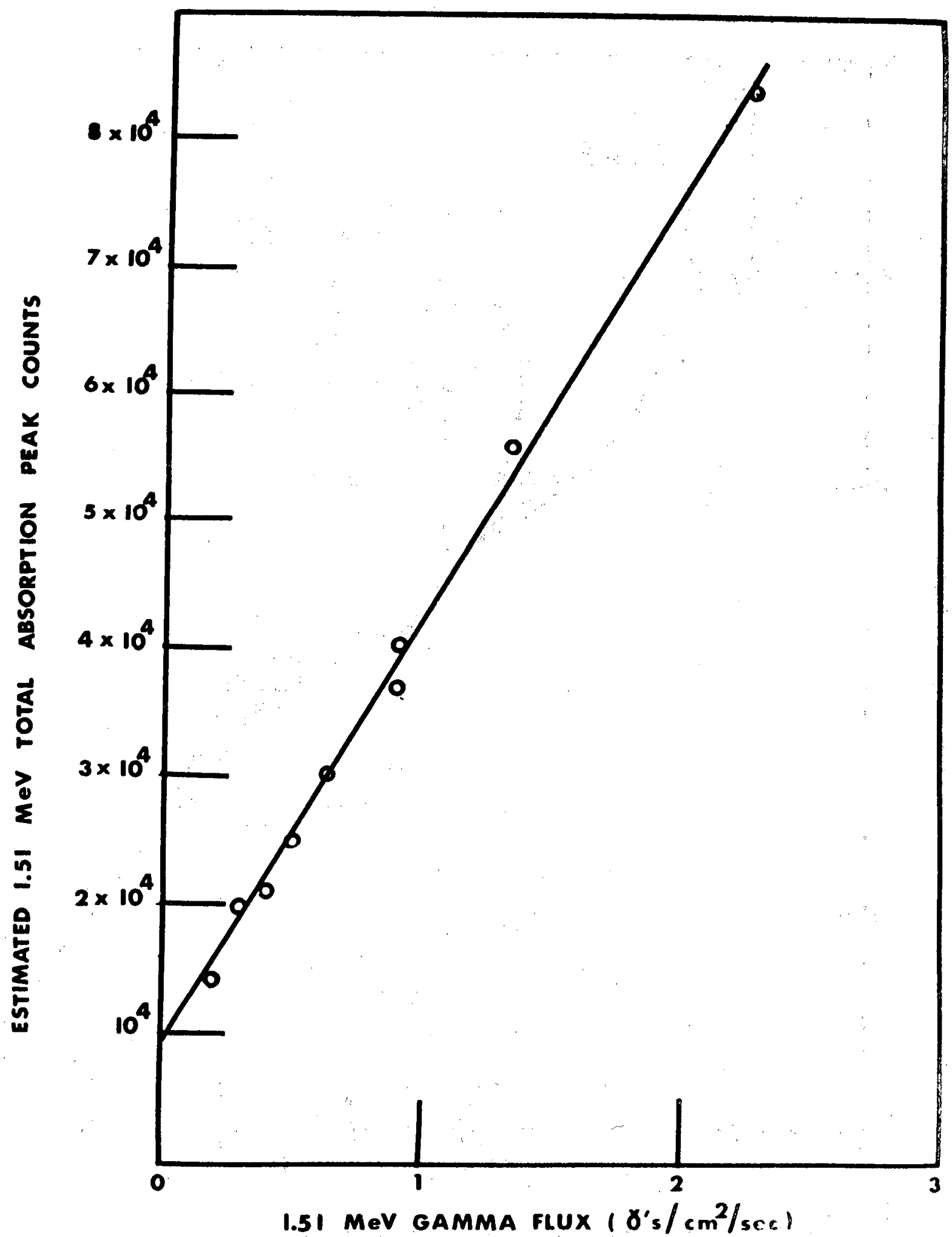

Figure 13. Determination of estimated $\mathrm{K}^{42}$ total absorption peak counts per unit incident primary flux $\left(N_{O} / \Phi\right)$. The laboratory background $K^{40}$ peak was estimated to be $9500 \pm 500$ counts. 


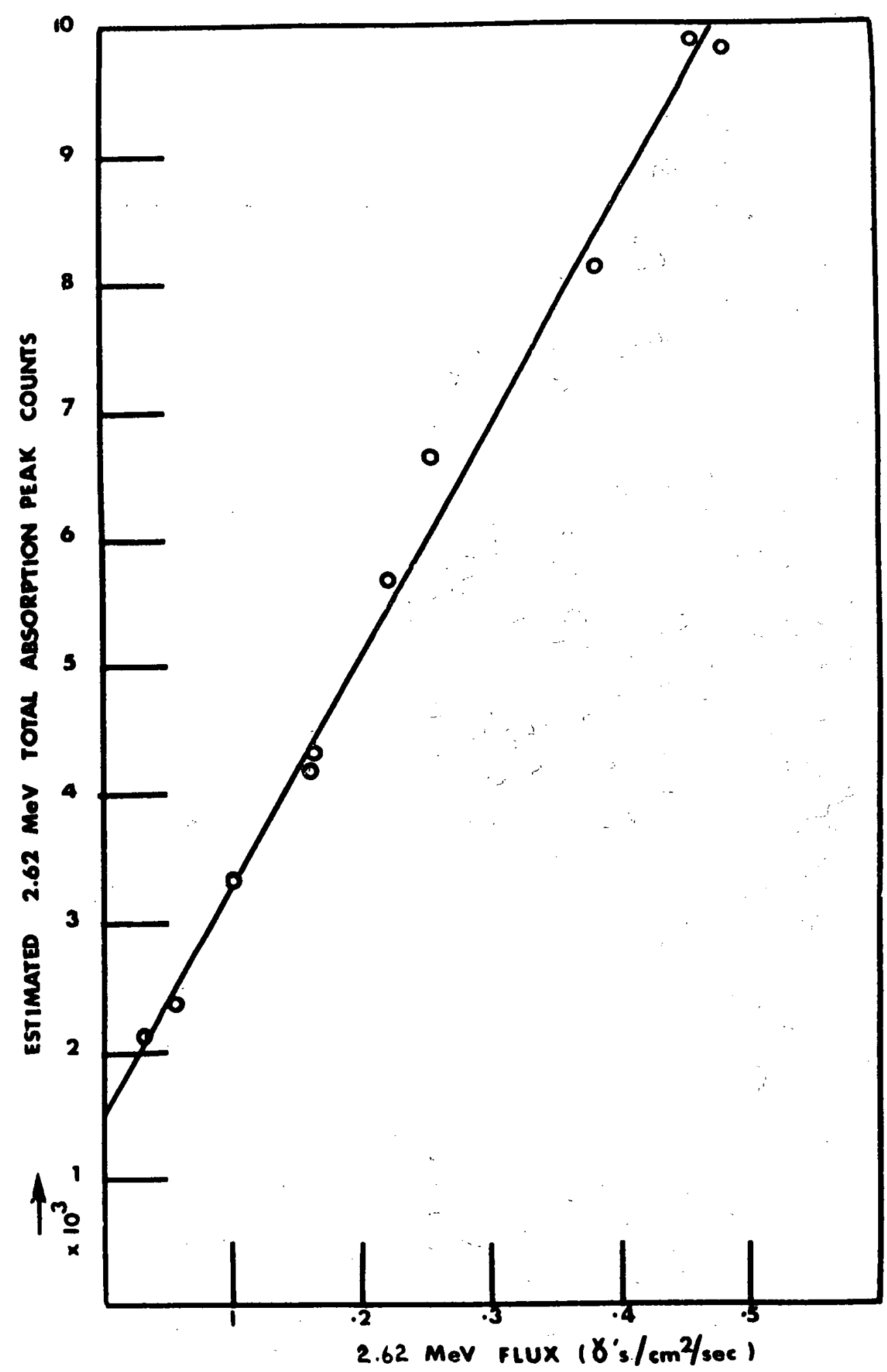

Figure 14. Determination of estimated Tl208 (2.62 MeV) total absorption peak counts per unit incident primary flux $\left(\mathrm{N}_{\mathrm{O}} / \Phi\right)$. The laboratory background peak, was estimated to be $1450 \pm 150$ counts. 


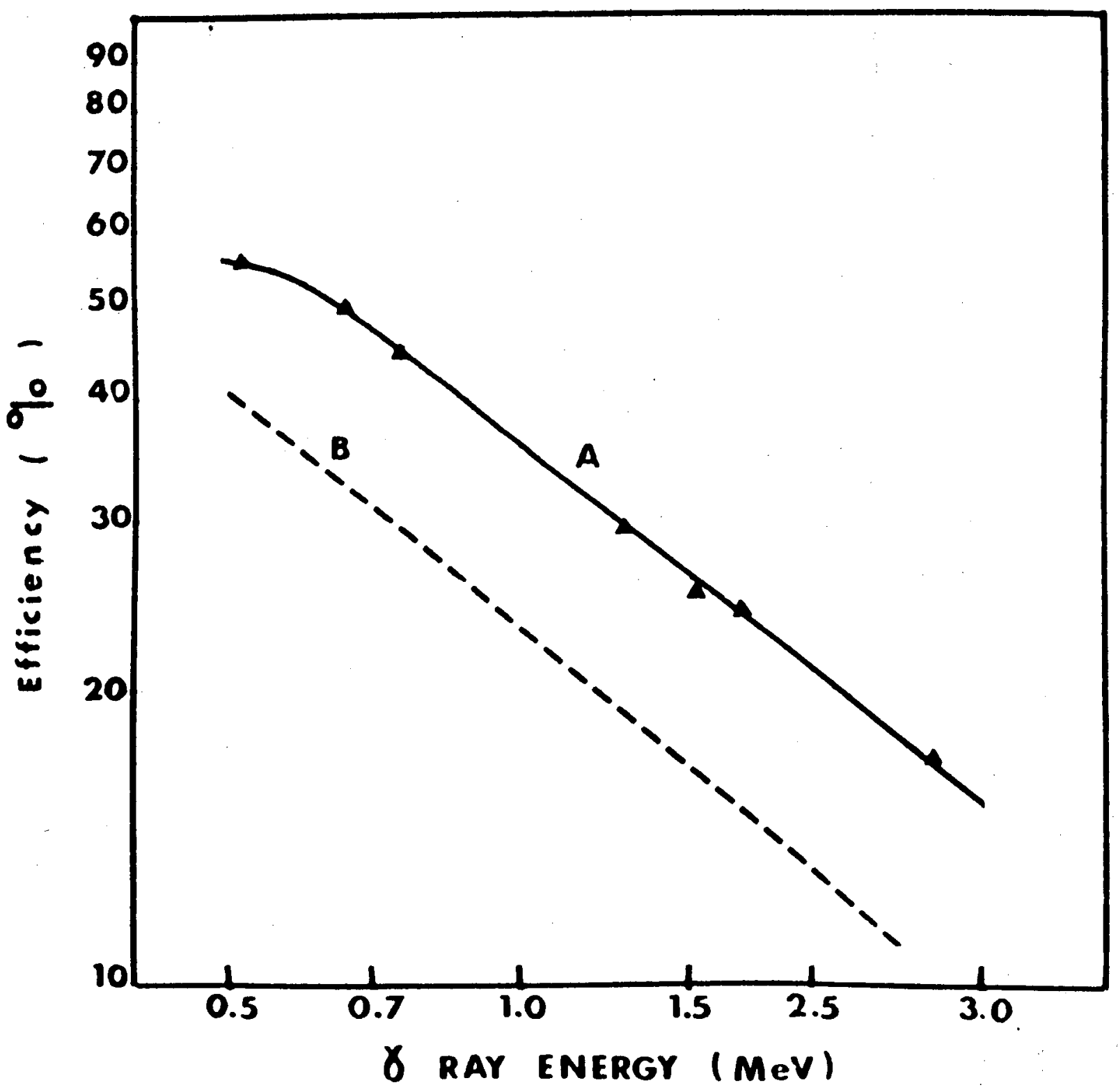

Figure 15. Intrinsic peak efficiency (ratio of counts in total absorption peak to number of incident $\gamma$-rays). A - HASL 5" x 3" NaI(TI) crystal; B - 3" x 3" NaI(TI) crystal (from Lazar et al. as reproduced in reference 14 ). 


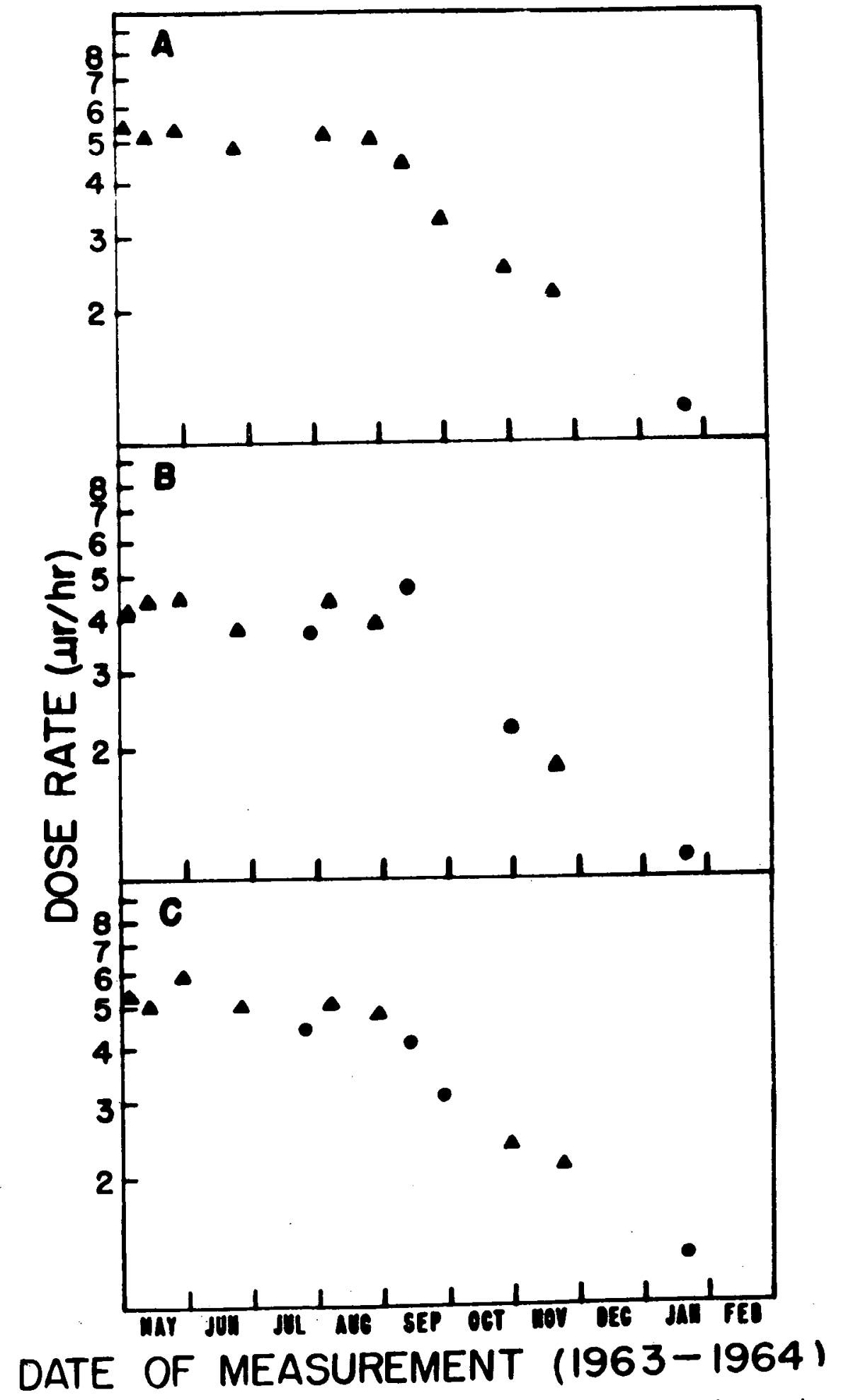

Figure 16. Fallout $\gamma$-ray dose rates at three locations in Westchester Co., N. Y.; A - Pelham, B - West Harrison, and C - Mamaroneck. The triangles refer to spectrometer readings and the circles to readings with the ionization chamber only. 


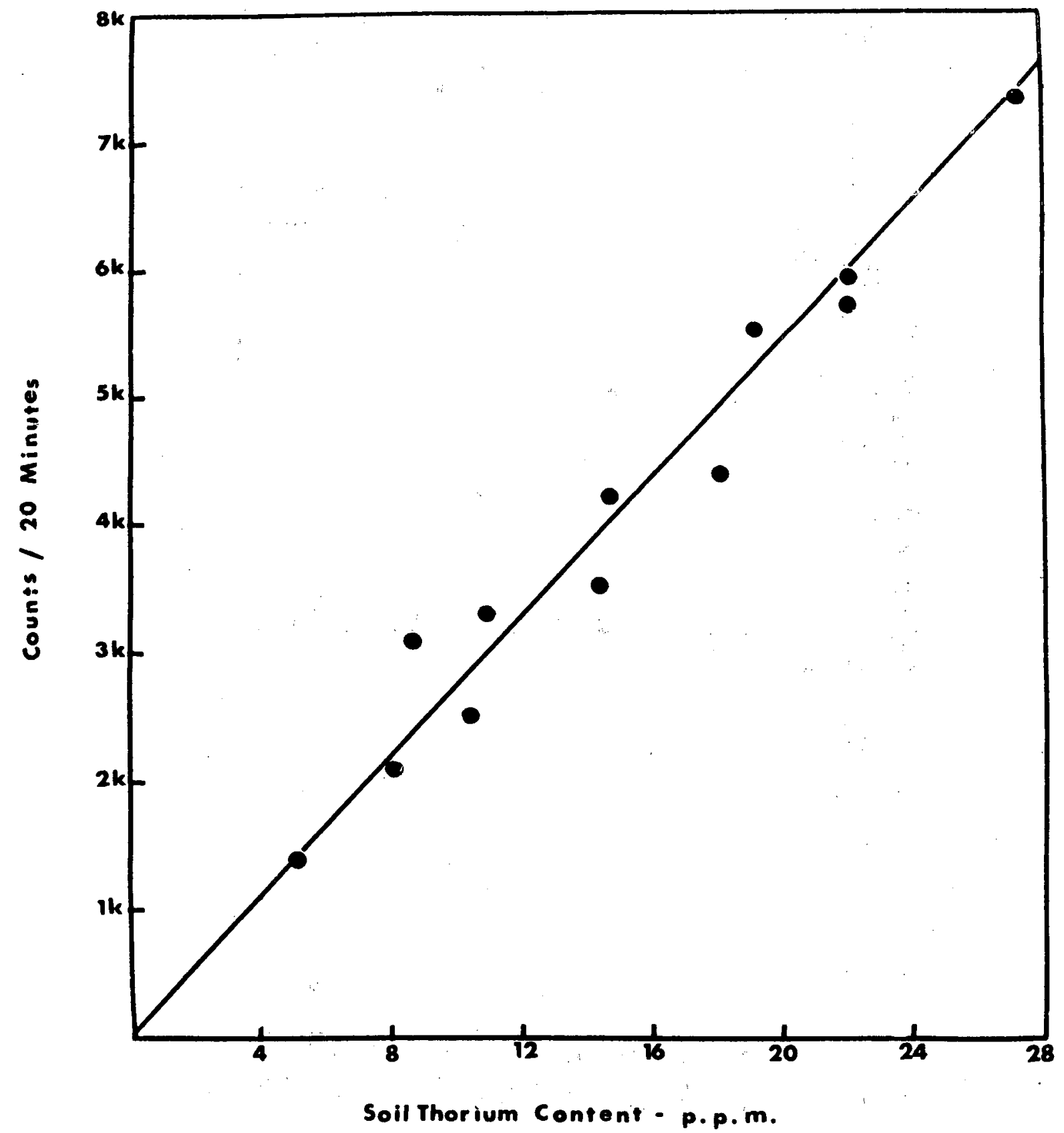

Figure 17. $2.62 \mathrm{MeV}$ absorption peak counts vs. Rice Univ. in situ Th232 soil content determinations. The solid line corresponds to the independent HASL calibration. 


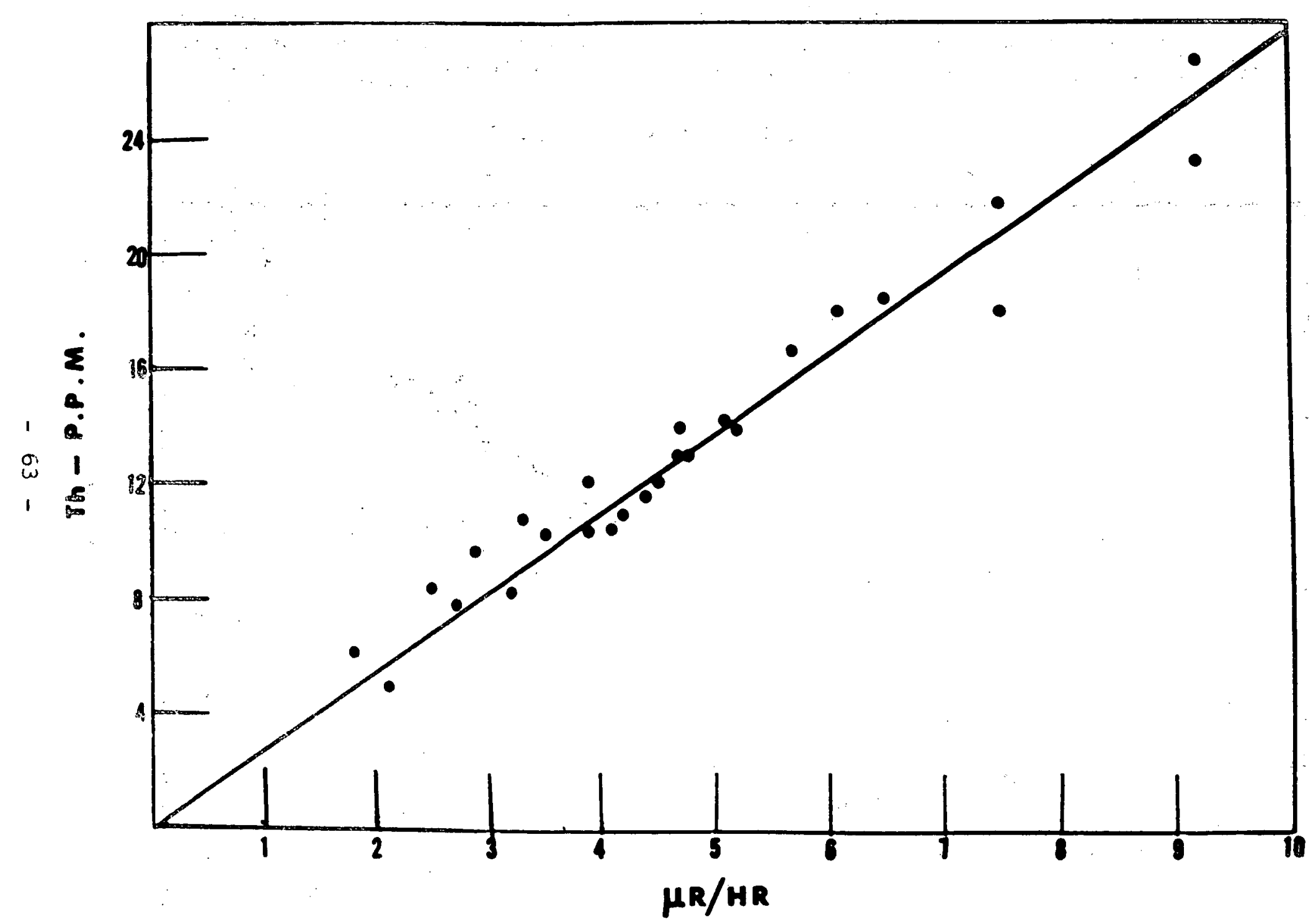

Figure 18. Rice Univ. in situ Th232 soil content vs. HASL energy band $T^{232}$ dose rate determinations. The solid line corresponds to the theoretical. conversion from Th3? R.F.m. to $\mu \mathrm{r} / \mathrm{hr}$ given in Table tu. 


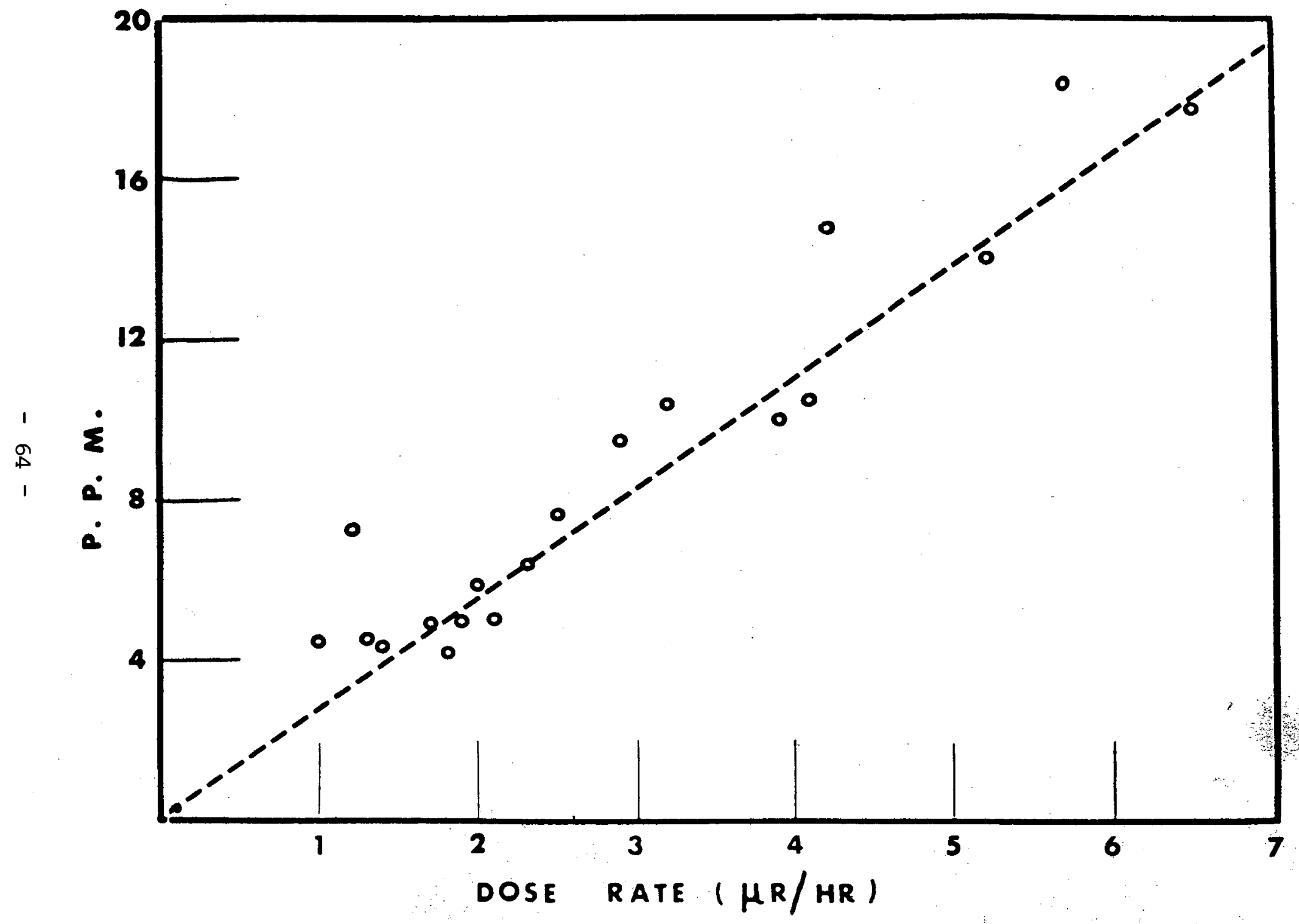

Figure 19. Th232 soil content determined by soil sample analysis vs. HASL Th232 series dose rate estimate. The solid line corresponds to the theoretical conversion from p.p.m. Th232 to $\mu \mathrm{r} / \mathrm{hr}$. 


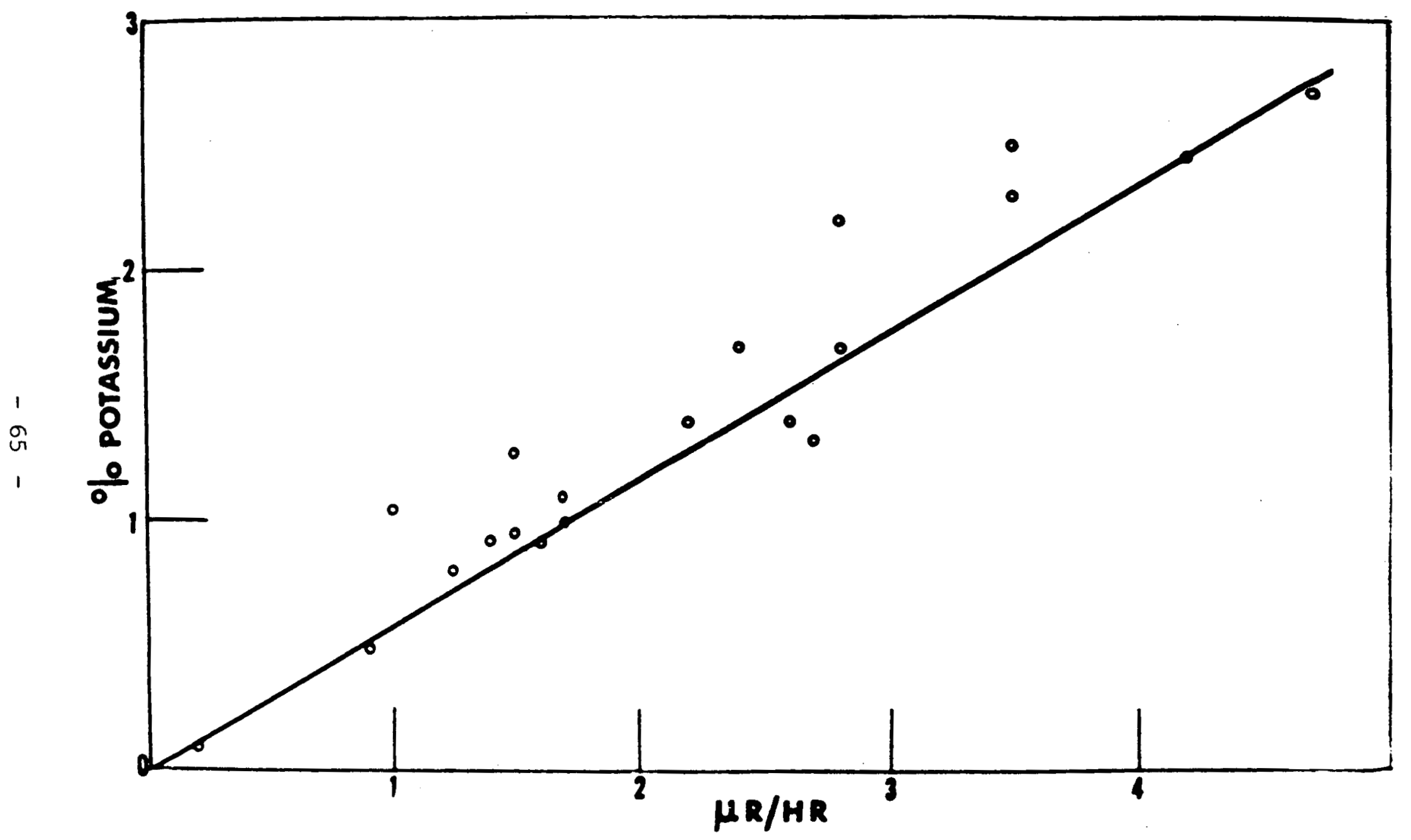

Figure 20. Potassium soil content determined by soil sample analysis vs. HALL $\mathrm{K}^{40}$ dose rate estimate. The solid line corresponds to the theoretical conversion from percent potassium to $\mu \mathrm{r} / \mathrm{hr}$. 


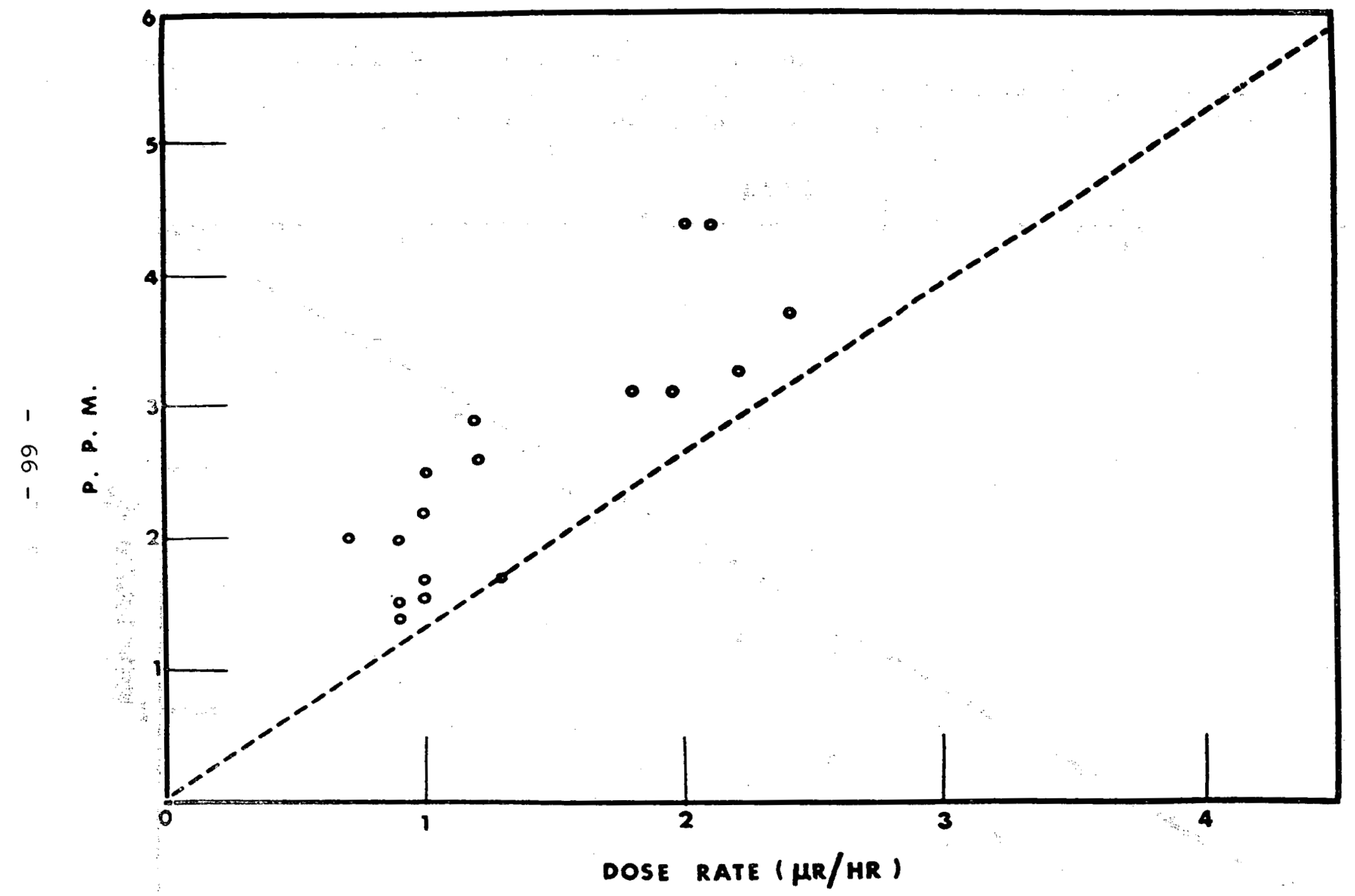

Figure 2l. $\mathrm{U}^{238}$ soil content determined by soil sample analysis vs. HASL U238 series dose rate estimate. The solid line corresponds to the theoretical. conversion from p.p.m. U238 to $\mu \mathrm{r} / \mathrm{hr}$ assuming secular equilibrium for the entire series and no loss of activity due to radon migration. 


$$
h
$$




\section{REFERENCES AND NOTES}

1. Solon, L. R., Lowder, W. M., Shambon, A., and Blatz, H., "Investigations of Natural Environmental Radiation", Science 131, No. 3404, 903 (March 25, 1960).

2. Shambon, A., Lowder, W. M., and Condon, W. J., "Ionization Chambers for Environmental Radiation Measurements", Health and Safety Laboratory Report, HASL-108 (February, 1963).

3. Lowder, W. M., Beck, H. L. and Condon, W. J., "The Spectrometric Determination of Dose Rates from Natural and Fallout Gamma Radiation in the United States, 19621963", Nature 202, No. 4934, 745 (May 23, 1964).

4. Lowder, W. M., Condon, W. J., and Beck, H. L., "Field Spectrometric Investigations of Environmental Radiation in the USA", in The Natural Radiation Environment, J. A. S. Adams and W. M. Lowder, eds. (Univ. of Chicago Press, Chicago, 1964).

5. Beck, H. L., Condon, W. J., and Lowder, W. M. "Environmental Radiation Measurements in the Southeastern, Central, and Western United States", Health and Safety Laboratory Report, HASL-145 (April, 1964).

6. Condon, W. J., Lowder, W. M., and Beck, H. L., "Environmental Radiation Measurements in New England", Health and Safety Laboratory report to be published.

7. Lowder, W. M., Beck, H. L., and Condon, W. J., "Environmental Radiation Measurements in New York State", HASL report to be published.

8. Lowder, W. M., Beck, H. L., and Condon, W. J., to be published. 
9. Gustafson, P. F. and Brar, S. S., "Measurement of Gamma Emitting Radionuclides in Soil and the Calculation of the Dose Arising Therefrom", in The Natural Radiation Environment, J. A. S. Adams and W. M. Lowder, eds. (Univ. of Chicago Press, Chicago, 1964).

10. Lough, S. A., and Solon, L. R., "The Natural Radiation Environment", Chapt. 17, Radiation Biology and Medicine, w. Claus, ed., Addison-Wesley, Reading, Mass. (1958).

11. Price, w. J., Nuclear Radiation Detection, p. 97, McGraw Hill, New York, (1958).

12. Ramm, w. J., "Scintillation Detectors", Chapt. 6, p. 266, Radiation Dosimetry, Hine and Brownell, eds., Academic Press, New York (1956).

13. Gustafson, P. F., Kastner, J., and Luetzelschwab, J., Science 145, No. 3627,44 (July 4, 1964).

14. Price, W. J., Nuclear Radiation Detection, p. 193, McGraw Hill, New York (1958).

15. Hultqvist, B., "Studies of Naturally Occuring Ionizing Radiations, with Special Reference to Radiation Doses in Swedish Houses of Various Types." Kungl. Svenska Vetenskapsakad. Handl. 6 Ser. 4., No. 3, p. 125 (1956).

16. O'Brien, K., Lowder, W. M., and Solon, L. R., "Beta and Gamma Dose Rates from Terrestrially Distributed Sources", Radiation Research 9, 216-21 (1958).

17. Evans, R., The Atomic Nucleus, p. 713, McGraw Hill, New York (1955).

18. Gustafsoń, P. F., "Measurement of Soil Radioactivity and Calculation of the Dose Therefrom", Argonne National Lab. Rept. ANL-5967, p. 156 (1959).

19. Friend, J. P. (ed.) "The High Altitude Sampling Program Vol. 5", Defense Atomic Support Agency Report DASA-1300, Part III, Ch. 3 (1961). 
20. Telfair, D., and Luetzelschwab, J., "Penetration of Fallout Fission Products into an Indiana Soil", Science 138, 829-30 (1962).

21. Walton, A., "The Distribution in Soils of Radioactivity from Weapons Tests", J. Geophys. Res. 68, 1485-96 (1963).

22. O'Brien, K., Lowder, W. M., and Solon, L. R., "A SemiEmpirical Method of Calculating the Energy-Absorption Build-up Factor with an Application to a Uniformly Contaminated Space Having Spherical Boundaries", Nuclear Science and Engineering 3 , 77 (1958).

23. Gibson, J. A. B, U.K. Atomic Energy Authority Report AERE-R 4137 (1962).

24. Wollenberg, H. A., and Smith, A. R., "Studies in Terrestrial Gamma Radioactivity", in The Natural Radiation Environment, J. A. S. Adams and W. M. Lowder, eds. (Univ. of Chicago Press, Chicago, 1964).

25. Foote, Robert S., "Time Variation of Terrestrial Gamma Radiation, " Ibid.

26. Thompson, T. and Wiberg, P. A., "Some Observations of Variations of the Natural Background Radiation" Tellus 15, No. 3, p. 313 (August 1963).

27. Adams, J. A. S., and Fryer, G. E. , "Portable Gamma-Ray Spectrometer for Field Determination of Thorium, Uranium, and Potassium", in The Natural Radiation Environment, Ibid.

28.' Adams, J. A. S., "Laboratory Gamma-Ray Spectrometer for Geochemical Studies", Ibid.

29. Kraner, H. W. , Schroeder, G. L., and Evans, R. D., "Measurements of the Effects of Atmospheric "Variables on Radon-222 Flux and Soil Gas Concentrations", Ibid.

30. Baranov, V. L., as quoted in Grammokov, A. B., "Field Emanation Method", Radiometric Methods in the Prospec- 
ting and Exploration of Uranium Ores. Moscow: state Sciencific - Technical Publishers of Literature of Geology and Mineral Resources Conservation (1957). [In English transl. USAEC Report AEC-tr-3738(1959)].

31. Vinogradov, A. P., The Geochemistry of Rare and Dispersed Chemical Elements in Soils: Ch. 16 (2nd ed., revised and enlarged). Translated from Russian: New rork: Consultants Bureau, p. 212 (1959).

32. Pearson, J. E., private communication. See also appendix in The Natural Radiation Environment, J. A. S. Adams and W. M. Lowder, eds. (Univ. of Chicago Press, Chicago, 1964).

33. Placzek, G., National Research Council of Canada report N.R.C. No. 1547 , p. 3 .

34. Hallden, N. A., Fisenne, I. M., Ong, L. D. Y., and Harley, J. H., Health and Safety Laboratory Report HASL-117, p. 194 (1961). 